\title{
How important is CRISPR-Cas for protecting natural populations of bacteria against infections by mobile genetic elements?
}

\author{
Edze Westra ${ }^{1}$, Bruce Levin ${ }^{2}$ \\ Authors contributed equally \\ ${ }^{1}$ Environment and Sustainability Institute, Biosciences, University of Exeter, \\ Cornwall Campus, Penryn, Cornwall TR10 9FE, United Kingdom \\ ${ }^{2}$ Department of Biology, Emory University, Atlanta, GA 30307, USA.
}

\begin{abstract}
Articles on CRISPR commonly open with some variant of the phrase 'these short-palindromic repeats and their associated endonucleases (Cas) are an adaptive immune system that exists to protect bacteria and archaea from viruses and infections with other mobile genetic elements'. There is an abundance of genomic data consistent with the hypothesis that CRISPR plays this role in natural populations of bacteria and archaea, and experimental demonstrations with a few species of bacteria and their phage and plasmids show that CRISPR-Cas systems can play this role in vitro. Not at all clear are the ubiquity, magnitude and nature of the contribution of CRISPR-Cas systems to the ecology and evolution of natural populations of microbes, and the strength of selection mediated by different types of phage and plasmids to the evolution and maintenance of CRISPRCas systems. In this perspective, with the aid of heuristic mathematical-computer simulation models, we explore the a priori conditions under which exposure to lytic and temperate phage and conjugative plasmids will select for and maintain CRISPR-Cas systems in populations of bacteria and archaea. We review the existing literature addressing these ecological and evolutionary questions and highlight the experimental and other evidence needed to fully understand the conditions responsible for the evolution and maintenance of CRISPR-Cas systems and the contribution of these systems to the ecology and evolution of bacteria, archaea and the mobile genetic elements that infect them.
\end{abstract}

\section{Significance}

There is no question about the importance and utility of CRISPR-Cas for editing and modifying genomes. On the other hand, the mechanisms responsible for the evolution and maintenance of these systems and the magnitude of their importance to the ecology and evolution of bacteria, archaea and their infectious DNAs, are not at all clear. With the aid of heuristic mathematical computer simulation models and reviews of the existing literature, we raise questions that have to be answered to elucidate the contribution of selection - mediated by phage and plasmids - to the evolution and maintenance of this adaptive immune system and its consequences for the ecology and evolution of prokaryotes and their viruses and plasmids. 


\section{Introduction}

In 1987, a study by Ishino and colleagues aimed at analyzing the nucleotide sequence of the iap gene (isozyme-converting alkaline phosphatase) in Escherichia coli serendipitously led to the firstever description of a CRISPR array. Specifically, they identified 14 repetitive sequences of 29 base pairs each at the 3' end of the iap gene, that were interspersed by 32-33 bp variable sequences $(1,2)$. Over the next years, identification of CRISPR arrays in other Gram-negative bacteria, Gram-positives and in Archaea (3-7) triggered a quest to identify their biological function (reviewed in (8)). Meanwhile, as more whole-genome sequences became available and CRISPR detection algorithms were developed, it became clear that these arrays of repeating sequences are common in prokaryotes, with estimated frequencies of approximately $30-40 \%$ in Bacteria and $90 \%$ in the Archaea (9-13), with clear variation between phyla (14). An important step in understanding the function of CRISPRs was the identification of so-called cas genes (for CRISPR-associated) that are often found in the neighborhood of CRISPR arrays (15). Bioinformatics analyses expanded the known repertoire of cas genes $(11,16-19)$, shed light on their evolutionary origins $(20,21)$ and led to a comprehensive classification of cas gene combinations into two classes, and an increasing number of types and subtypes of CRISPR-Cas systems that differ in key mechanistic aspects (12).

The original idea that CRISPR-Cas is an adaptive immune system came from observations that sequences in CRISPR arrays on the chromosomes of bacteria match those of phage and other foreign genetic elements $(10,22,23)$. Cas genes were - based on their domains and predicted catalytic activities - suggested to encode the protein machinery that carries out the various steps of the immune response (11). The first experimental evidence in support of this hypothesis came from a joint effort by industrial and academic partners, who showed that the lactic acid bacterium Streptococcus thermophilus acquired post-infection resistance (hereafter immunity) against viral infection by inserting sequences from the viral genome into CRISPR loci on the bacterial genome (24). Viruses in turn were found to overcome CRISPR-based immunity by mutation of the target sequence on their genome (25). Together, these findings fueled models of how bacteria with CRISPR systems and their viruses might coevolve (26-28). In parallel with this experimental work, genomic data suggested that CRISPR loci evolve rapidly in natural populations of acidophilic bacteria (29), and that the DNA sequences between these palindromic repeats, spacers, were homologous to that of phage, plasmids and transposons (30).

Since these pioneering studies, spacer uptake from phages and other mobile genetic elements in bacteria and archaea from natural and human-associated environments has been inferred from variation in spacer sequences within and between populations of the same species and from their homology to mobile genetic element (MGE) genomes (31-40). Experimental observations of spacer uptake in the lab in response to plasmid and phage infection have been made amongst others in engineered E. coli strains (41-43) and Staphylococcus aureus (44-47) and in wild type Pectobacterium atrosepticum (48), Pseudomonas aeruginosa (49, 50), Roseburia intestinalis (51), Sulfolobus solfataricus (52), Streptococcus mutans (37) and other species (reviewed in (53)). Consistent with the hypothesis that CRISPR-Cas protects bacteria from infections, some mobile genetic elements encode so-called anti-CRISPR genes (reviewed in (54)).

\section{How important is CRISPR to the ecology and evolution of bacteria and archaea?}

While the preceding evidence and arguments demonstrate that CRISPR-Cas can protect bacteria and archaea from infectious DNAs, it is not at all clear how commonly CRISPR plays this role in 
natural populations of these microbes. If CRISPR commonly protects bacteria from infectious DNAs, one might expect a strong negative correlation between the presence of a CRISPR system and the signatures of horizontal gene transfer in the same genomes. For Restriction-Modification systems - the most prevalent innate immune system of bacteria and archaea - such correlations can be readily detected (55). Yet, in the case of CRISPR-Cas the evidence is ambiguous, with some studies suggesting that CRISPR does form a barrier for the movement of mobile genes between microbial species $(56,57)$, whereas other studies arrive at the opposite conclusion $(58$ $60)$. Furthermore, most spacers from sequenced isolates have no homology to viral or plasmid sequences in databases (40) and the same holds for spacers extracted from metagenomes (39).

If indeed CRISPR-Cas is commonly important for protecting populations of microbes from phage and preventing the acquisition of mobile genetic elements, there should be no trouble detecting (in the lab or in nature) CRISPR-Cas-encoding bacteria and archaea that acquire spacers from novel sources of infectious DNAs to become immune to those infections. However, other than the bacterial species listed above, there are very few wildtype bacteria or archaea for which spacer acquisition from phage or plasmids has been demonstrated to occur at observable frequencies. Moreover, even for species that have been reported to acquire spacers, it is not clear whether they do so in response to only few or many phages and plasmids. Because in most bacteria and archaea spacer acquisition is rare, a range of elegant tricks have been developed to detect these events (44, 61-66), and while this has propelled our understanding of the mechanisms of spacer acquisition (53), and CRISPR-mediated immunity (67), it raises questions concerning the ecological importance of CRISPR-Cas immune systems. Perhaps this is because many of the domesticated bacteria and archaea that we use for research simply lost their ability to rapidly acquire spacers? Could it be that the quest to find culturable bacteria, archaea, phage and plasmids with these properties has not be adequately extensive? Or could it be that the results of these quests are commonly negative and therefore not reported? Sequence data analysis also provides a mixed picture: CRISPR loci in some species appear to evolve rapidly, e.g. refs. $(29,30,32)$ and reviewed in (68), whereas others are relatively static over long periods $(60,69)$.

\section{Open questions}

We hope the preceding has convinced the reader that how commonly CRISPR-Cas systems protect populations of bacteria and archaea from infections with deleterious mobile genetic elements, and the corollary, that extant CRISPR-Cas systems are maintained by selection mediated by these infectious genetic elements, are open questions. To address these issues, we explore the answers to the following four questions:

1- Under what conditions will immunity be selected for in populations with functional CRISPRCas systems (CRISPR ${ }^{+}$bacteria and archaea) confronted with phage and plasmids?

2- Under what conditions will bacteria and archaea with functional CRISPR-Cas immune systems invade from rare upon infection with phage and plasmids, and become established in populations that lack CRISPR-Cas systems (CRISPR- bacteria and archaea)?

3- What is the contribution of CRISPR immunity to the population dynamics, ecology and evolution of prokaryotes and their mobile genetic elements?

4- What are the characteristics of mobile genetic elements that lead to spacer acquisition by bacteria during an infection? 
We explore the first three of these questions in two ways, (i) with heuristic, mathematicalcomputer simulation models of the dynamics of microbes and infectious genetic elements, and (ii) with a review of the experimental and other empirical studies that provide some answers to these questions. We separately consider the three main sources of infectious DNAs: lytic phage, temperate phage, and conjugative plasmids. For each of these we consider the invasion conditions: the conditions under which selection mediated by these infectious mobile genetic elements will (i) lead to the ascent of immune cells in populations with functional CRISPR-Cas mediated immunity, $\mathrm{CRISPR}^{+}$, and (ii) the establishment of CRISPR-Cas, CRISPR ${ }^{+}$, in populations that do not have a functional CRISPR-Cas system, CRISPR-. The equations for the models used and those employed for the analysis of their properties are presented in the Supplemental Material, as are the caveats and concerns about the limitations of these models and our analyses of their properties.

\section{I - Lytic phage.}

What the models and theory tell us: We use a simple model, that captures the molecular mechanism of Type I and II CRISPR-Cas systems, which are the most abundant systems $(30 \%$ and $8 \%$ of genomes, respectively (70)). In this model, there is single population of lytic phage, $\mathrm{V}$, a population of bacteria that lacks a functional CRISPR-Cas system and a population that carries a functional CRISPR-Cas system, respectively CRISPR ${ }^{-}$and CRISPR $^{+}$. The CRISPR ${ }^{-}$bacteria are of two possible states, phage sensitive, $\mathrm{S}$, and phage resistant, $\mathrm{SR}$, due to phage receptor mutations. The $\mathrm{CRISPR}^{+}$bacteria can be of three states, phage sensitive not immune, $\mathrm{C}$, phage resistant, CR, due to phage receptor mutations, and phage immune, $\mathrm{CI}$, due to the acquisition of a phage-targeting spacer in the CRISPR array (Figure S1). We assume that resistant bacteria, SR and CR, are refractory to the phage; the phage do not adsorb to these cells. By contrast, immune bacteria, CI, can be infected by the phage, but phages do not replicate and are lost. Resistance is acquired by random mutation, and immunity through the acquisition of a spacer by infection with the phage. Both acquisition of a resistance mutation and the acquisition of spacers are stochastic processes which we model with a Monte Carlo protocol.

First, we consider the conditions under which resistance, CR, and CRISPR-Cas-mediated immunity, CI, will invade a $\mathrm{CRISPR}^{+}$phage-sensitive population, $\mathrm{C}$, at equilibrium with the phage. If the $\mathrm{CRISPR}^{+}$population, $\mathrm{C}$, is unable to generate resistant mutants, $\mathrm{CR}$, but can acquire spacers, and the likelihood of acquiring a spacer upon infection with the phage is on the order of $10^{-8}$ or greater, there are broad conditions under which CRISPR-Cas will be selected for and immune cells CI will become established in a CRISPR ${ }^{+}$population. This can be seen from the change in the mean densities of immune cells in Figure 1A. If both immunity and resistance can be generated, both will become established (Figure 1A). For examples of the associated population dynamics, see Figure S2A-C in the supplemental material. In the simulations presented in Figure $1 \mathrm{~A}$, upon first encounter with the phage, immunity and resistance are equally likely to be generated and therefore resistant and immune cells are equally likely to ascend to dominate the CRISPR ${ }^{+}$ population (we assume no costs of resistance). If immunity is 10 -fold more likely to be generated than resistance, immune cells are more likely to dominate the population (Figure S2D).

The conditions for bacteria with CRISPR-Cas $\left(\mathrm{CRISPR}^{+}\right)$to become established in a CRISPRpopulation of sensitive bacteria at equilibrium with a lytic phage are more restrictive than that for CRISPR-Cas-mediated immunity to become established in a population of CRISPR ${ }^{+}$bacteria. 
When the frequency of the invading population of CRISPR ${ }^{+}$cells is low, $10^{-4}$ or less, the CRISPR ${ }^{+}$ population does not become established (Figure 1B). Moreover, in only 2 or the 200 runs did the $\mathrm{CRISPR}^{+}$become invade when the initial frequency of CRISPR ${ }^{+}$was $10^{-3}$. The reason for the difficulty of CRISPR ${ }^{+}$bacteria to become established in CRISPR ${ }^{-}$populations when bacteria with this immune system are initially rare is that, when confronted with phage, resistant mutants are likely to be generated in the dominant population of CRISPR ${ }^{-}$sensitive cells (see Figure S3A-C). The conditions for the invasion of $\mathrm{CRISPR}^{+}$in a CRISPR ${ }^{-}$population are greater if the rate of spacer acquisition is higher or if the CRISPR- population is unable to generate resistant mutants (Supplemental Figure S3DE)
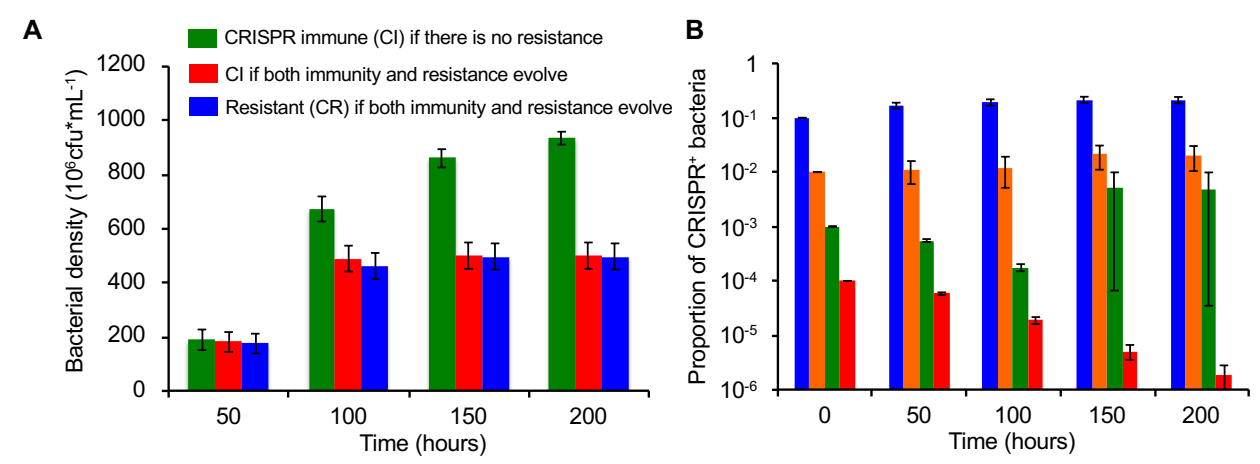

Figure 1. Lytic phage-mediated selection for CRISPR-Cas mediated immunity and envelope resistance. Invasion conditions: (A) Monte Carlo simulations of selection for CRISPR-Cas immunity and resistance in a CRISPR ${ }^{+}$phage-sensitive population initially at equilibrium with the phage. Mean and standard error of the changes in density of CRISPR ${ }^{+}$immune and resistant bacteria across 100 runs. Green bars are for a population of CRISPR ${ }^{+}$bacteria that cannot generate resistant mutants. Red and blue bars are for populations that can evolve both CRISPR-Cas immunity (red bars) and envelope resistance (blue bars) with equal probabilities. (B) Invasion of $\mathrm{CRISPR}^{+}$into a population of CRISPR ${ }^{-}$sensitive bacteria at equilibrium with phage, with different initial frequencies of $\mathrm{CRISPR}^{+}$(blue $=0.1$, orange $=0.01$, green $=0.001$, red $=0.0001$ ). Resistant and immune bacteria can be generated in the invading $\mathrm{CRISPR}^{+}$population and resistance can be generated in the initially dominant CRISPR ${ }^{-}$population. Mean and standard error of the frequency of $\mathrm{CRISPR}^{+}$bacteria over time across 200 runs. Parameters: $\mathrm{v}_{\mathrm{C}}=\mathrm{v}_{\mathrm{CI}}=\mathrm{v}_{\mathrm{CR}}=0.7, \delta=10^{-7}, \beta=50$, $\mathrm{e}=5 \times 10^{-7}, \mathrm{k}=1, \mathrm{RR}=500, \mathrm{w}=0.1, \mathrm{r}(0)=500, \mu_{\mathrm{SR}}=10^{-8}, \mu_{\mathrm{RS}}=10^{-8}, \mathrm{x}=1.667 \times 10^{-8}$ and the total volume of the vessel is $\mathrm{Vol}=100 \mathrm{ml}$. The initial densities of bacteria and phage in these simulations are at the equilibrium for a phage-limited population, respectively, $\mathrm{C}^{*}=2 \times 10^{4}, \mathrm{~V}^{*}=6 \times 10^{6}$.

The invasion theory considered above addresses only one element of the role of phage in the evolution of CRISPR-Cas. The other element is the length of time selection mediated by lytic phage will favor CRISPR-Cas immune systems. This will depend on (i) the capacity of the phage to generate protospacer mutants, (ii) the capacity of the bacteria to acquire novel spacers to counter protospacer mutations in the phage, (iii) the rates at which these novel spacers are acquired, (iv) 
the rate of mutation to resistance, and (v) the fitness costs associated with the carriage of CRISPRCas, surface resistance, and protospacer mutations in the phage. Some theoretical studies have partly addressed this issue $(27,28,71)$, but the models employed do not consider all five of the above-listed factors contributing to the length of time selection for CRISPR-Cas will be maintained.

\section{What the experiments and genomic data say:}

While we are unaware of experimental studies that examine the invasion of $\mathrm{CRISPR}^{+}$into established CRISPR- populations of bacteria or archaea, there have been several experimental studies of the population and evolutionary dynamics of lytic phage and bacteria with CRISPR-Cas systems. As anticipated by the models, CRISPR-Cas immunity readily evolves in S. thermophilus strains exposed to virulent phage $(24,72)$. In this system, bacteria with envelope resistance are normally not detected and an extended spacer - protospacer arms race can ensue when these bacteria and phage are together in serial transfer culture $(24,73-75)$. While the phage will eventually be lost, the duration of the arms race and the diversity of spacers and phage protospacer mutants that evolves during this process can be substantial. In these experimental populations, the densities of bacteria remain at levels similar to that of phage-free populations. Stated another way, the bacterial populations are limited by resources, rather than the phage.

In these experiments, it is clear that the co-evolutionary dynamics observed for $S$. thermophilus and its phage can be attributed to CRISPR-Cas-mediated immunity to the phage. Resistant bacteria only evolve if the CRISPR-Cas system is inactivated by either anti-sense RNA expression (76) or an antiCRISPR (acr) gene encoded by the phage (77), with resistance due to mutations in either the receptor or intracellular host genes required for completing the phage life cycle. This system, therefore, corresponds well with the theoretical scenario in Figure 1A (green bars), which therefore may explain why the evolution of CRISPR immunity is so commonly observed in this model organism.

Also consistent with the theoretical predictions are the results of experiments with bacteria that can evolve both CRISPR immunity by the acquisition of spacers and resistance by mutation of the phage receptors. For example, Pseudomonas aeruginosa strain PA14 either evolves resistance against phage DMS3vir (a temperate phage locked in the lytic cycle) by mutation of the Type IV pilus or immunity by the acquisition of spacers into its CRISPR arrays (49, 50). Experimental manipulation of the bacterial mutation rate shows that which of these two defense mechanisms prevails strongly depends on the rate at which receptor mutants are generated in the population (78). Similarly, the rates of spacer acquisition matters: bacteria with "primed" CRISPR-Cas systems acquire spacers at a higher rate compared to bacteria with naïve CRISPR-Cas systems; this translates in a strong increase in the proportion of bacteria that evolved CRISPR-Cas immunity following phage exposure $(41,42,48,61,79-82)$. This phenomenon was observed first for many Type I where it relies on an imperfect match between a pre-existing spacer and the infectious genome (see ref. (53) for mechanistic details) and, more recently, a similar mechanism was also observed for Type II CRISPR-Cas systems $(47,79)$. When bacteria are exposed to defective phage, or when bacteria carry both a restriction-modification and a CRISPR-Cas system, the rates of spacer acquisition are also elevated, and again this leads to higher levels of evolved CRISPR immunity $(83,84)$. The typically low frequencies of CRISPR immunity that many bacteria evolve in the lab may therefore be at least in part explained by the high mutation rates and large population sizes relative to the rates of spacer acquisition in many model systems, although the fitness costs 
and benefits of CRISPR-based immunity and surface-based resistance will also be important (50, 85), which has been reviewed elsewhere (86).

\section{II - Temperate phage.}

What the models and theory tell us: In our model, (depicted in Figure S4), there is a single population of free temperate phage, $\mathrm{P}$, and five populations of bacteria. Bacteria that lack a functional CRISPR-Cas system, CRISPR-, can exist in two states: susceptible non-lysogens, S, and lysogens, L. Bacteria that carry a functional CRISPR-Cas system, CRISPR ${ }^{+}$, can exist in three states: sensitive non-lysogens, C, lysogens, CL, or CRISPR-immune, CI. Infections occur at random at a rate proportional to the product of the densities of free temperate phage, $\mathrm{P}$, and the bacteria. Lysogens and CRISPR immune bacteria can be infected by free phage, but the phage do not replicate and are removed from the free phage population. Upon infection of CRISPR ${ }^{-}$sensitive cells, $\mathrm{S}$, a fraction $\lambda(0 \leq \lambda \leq 1)$ produce lysogens, $\mathrm{L}$. The remaining $(1-\lambda)$ infections results in lysis of the host to generate free phage (i.e. the lytic cycle) (87). Infections of CRISPR ${ }^{+}$sensitive cells, $\mathrm{C}$, have three possible outcomes: a fraction $\lambda(0 \leq \lambda \leq 1-\mathrm{x})$ produce lysogens, CL with the remaining $(1-\mathrm{X}-\lambda)$ producing lytic infections and killing the infected host. By the acquisition of a spacer from the phage, a fraction $\mathrm{x}(0 \leq \mathrm{x} \leq 1)$ of the infections produce CRISPR-Cas immune cells, CI. In addition, at a rate $\mathrm{y}(0 \leq \mathrm{y} \leq 1)$ CRISPR-Cas immune cells are generated by lysogens, through the acquisition of a spacer from the prophage. For this analysis, we are not considering lytic mutants of the temperate phage or envelope resistant mutants.

In Supplemental Figure S5 and Figure 2 below, we consider the conditions in which selection mediated by temperate phage will lead to the establishment of CRISPR-Cas immunity in a $\mathrm{CRISPR}^{+}$population and the establishment of bacteria with CRISPR-Cas (CRISPR ${ }^{+}$) in a CRISPRpopulation. During the early stages of infection, temperate phages mostly transmit horizontally through the lytic cycle and selection for CRISPR immunity will therefore initially be similar to that observed for the lytic phage (Figure 1 and S5A). Following this, a large subpopulation of lysogens will form that coexists with bacteria that acquired CRISPR immunity in response to horizontally transmitting phage (88). To explore the long-term selection pressures for CRISPR immunity and invasion of CRISPR ${ }^{+}$into CRISPR $^{-}$populations, we start our simulations when the bacterial populations are at equilibrium with the temperate phage and therefore dominated by lysogens (Figure S5B). Under those conditions, for selection mediated by temperate phage to lead to the establishment of CRISPR-Cas immune cells in populations with functional CRISPR-Cas systems, either lysogens have to generate immune cells or the prophage has to reduce the fitness of lysogens relative to non-lysogens (Figure 2A). The rate of ascent of the immune cells is inversely proportional to the fitness of the lysogens. For selection mediated by temperate phage to lead to the invasion of CRISPR ${ }^{+}$bacteria in a CRISPR ${ }^{-}$population, the fitness of lysogens needs to be less than or equal to that of non-lysogens. If the carriage of the prophage augments the fitness of the bacteria, as may be the case $(89,90)$, CRISPR immune bacteria will be selected against and the $\mathrm{CRISPR}^{+}$population will not be able to invade a population without this immune system (Figure 2B). (88) 


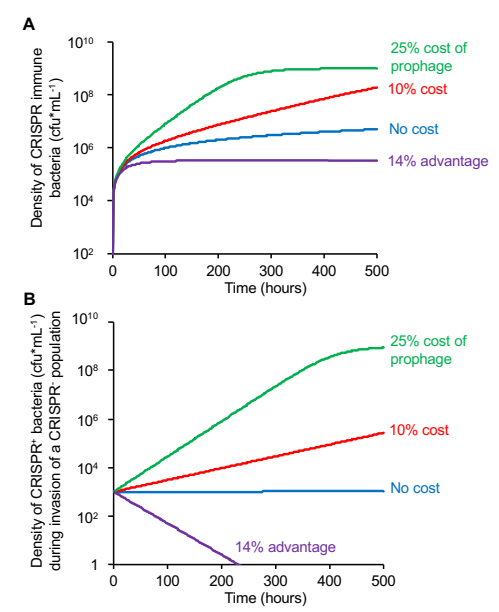

Figure 2 Selection-mediated by temperate phage. (A) The establishment of CRISPR immunity in a population of $\mathrm{CRISPR}^{+}$bacteria at equilibrium with a temperate phage. Changes in the density of CRISPR-Cas immune bacteria are depicted. (B) The invasion of CRISPR ${ }^{+}$bacteria into a population of CRISPR ${ }^{-}$bacteria at equilibrium with a temperate phage. Changes in the densities of $\mathrm{CRISPR}^{+}$bacteria are depicted. Carrying the prophage is associated with either a $14 \%$ advantage, a $10 \%$ cost, a $25 \%$ cost, or no cost, as indicated in the figure. For the parameter values, see Figure S5C and F.

What the experiments and data say: There is evidence that CRISPR-Cas systems target temperate phage in nature. For example, spacers encoded by $P$. aeruginosa isolates with Type I CRISPRCas systems from cystic fibrosis lungs were found to frequently target related groups of temperate phages (including DMS3). Surprisingly, however, in these patients, no spacer acquisition was observed over time (60). By contrast, in an experimental study where a wound model was infected with a mix of $6 P$. aeruginosa strains, CRISPR immunity was found to evolve in $P$. aeruginosa strain PA14 against a prophage carried by one of the strains, known as strain B23-2 (91). Another recent study with $P$. aeruginosa PA14 and its phage DMS3 showed that carrying a primed CRISPR-Cas immune system is, in fact, maladaptive during temperate phage infection, due to immunopathology in $\mathrm{CRISPR}^{+}$lysogens since the partial matching spacer triggers cleavage of the prophage. The associated fitness costs caused a rapid invasion of spontaneous mutants that had lost their CRISPR-Cas immune system (88). Acquisition of perfectly matching spacers in lysogens amplified these fitness costs, since this programs the immune system to attack the prophage inside the bacterial genome even more strongly. Such self-targeting by CRISPR-Cas is well known to be highly toxic (92-99), even for Type III CRISPR-Cas systems that target only transcriptionally active DNA $(100,101)$. Finally, a recent and exciting study showed that $R$. intestinalis in the mouse gut can evolve high levels of CRISPR-based immunity when one of its active prophages evolves to become hypervirulent (i.e. virulent phage mutants that can infect the lysogen) (51). This, however, brings us to what is anticipated for lytic phage. We are unaware of empirical studies that have explored the contribution of temperate phage to the establishment of CRISPR-Cas in CRISPR- populations. 


\section{III - Conjugative Plasmids.}

What the models and theory tell us: In our model of the population dynamics of CRISPR-Cas immunity and conjugative plasmids there are five populations of bacteria (Figure S6). Two lack a functional CRISPR-Cas system, are CRISPR', and can exist in two states: one carrying the plasmid and one not, respectively DP and S. Three populations carry a functional CRISPR-Cas system, $\mathrm{CRISPR}^{+}$, and exist in three states: plasmid-free, C, plasmid-bearing, $\mathrm{CP}$ and one that is plasmidfree but immune to the acquisition of the plasmid, CI. Plasmid transfer is by conjugation, which occurs via random contact between plasmid-bearing and plasmid-free cells (102). A "mating" between DP or CP and S produces SP. A fraction $\mathrm{x}(0 \leq \mathrm{x} \leq 1)$ of matings between DP or CP with $\mathrm{C}$ produce $\mathrm{CP}$, and the remaining fraction of the mating's, $(1-\mathrm{x})$, produce cells that remain plasmidfree but have acquired CRISPR immunity, CI. These CRISPR-Cas immune cells do not take up the plasmid.

The population dynamics of temperate phage and conjugative plasmids are different $(87,102)$ (compare the temperate phage dynamics in Figures S5A and D to the plasmid dynamics in Figures S7A and D). On the other hand, the conditions under which these infectiously transmitted genetic elements will favor the invasion of CRISPR-Cas immune bacteria into CRISPR ${ }^{+}$populations and $\mathrm{CRISPR}^{+}$bacteria into CRISPR ${ }^{-}$populations are virtually identical (Figures S7C and F). The reason for this is that simulations are initiated at equilibrium, and with the parameters used both of these infectiously transmitted genetic elements will sweep though the bacterial populations and at equilibrium cells carrying them are the dominant population. Whether CRISPR-Cas immune cells will invade and become established in populations with lysogens and bacteria carrying conjugative plasmids depends on the fitness cost of these genetic elements: the greater the cost the broader the conditions for the establishment and maintenance of these elements. As with temperate phage, if the plasmid increases the fitness of the bacteria, CRISPR-Cas immunity would be selected against (103).

What the experiments and data say: Experimental studies demonstrate that bacteria can evolve CRISPR-based immunity against plasmids, and in the case of Type I CRISPR-Cas systems, spacer acquisition is accelerated if the CRISPR immune system is primed. Most commonly this priming is accomplished by engineering the plasmid in a way that it contains a sequence with a partial match to a pre-existing spacer on the genome of a CRISPR ${ }^{+}$host $(41,48,61,104)$. As anticipated by the model, CRISPR immunity will be selected against if the plasmid provides a net benefit to the host, for example when it confers resistance to an antibiotic that is present in the environment. Rare mutants that lack an intact CRISPR-Cas immune system will quickly replace the dominant $\mathrm{CRISPR}^{+}$population (105). The model predicts that if the carriage of the plasmid engenders a fitness cost, CRISPR-mediated immunity to that plasmid will be favored. To our knowledge, this has not been demonstrated experimentally. Indeed, the evidence we are aware of is inconsistent with this hypothesis. A study with engineered E. coli strains showed that even under these conditions CRISPR immunity can be maladaptive, because the time between infection and clearance of the plasmid may allow for the expression of toxin/anti-toxin cassettes. This, in turn, triggers a significant cost of plasmid removal because (short-lived) antitoxin is no longer produced to neutralize the long-lived toxin molecules (106). How common this is, is not at all clear. We anticipate that CRISPR-immunity will be favored when the plasmid engenders a fitness cost, provided that any costs of plasmid removal do not outweigh the benefits of being plasmid-free. We are unaware of any experimental or other empirical studies that have addressed the question 
of the conditions under which plasmid-mediated selection will favor the invasion of bacteria with CRISPR-Cas systems into CRISPR- populations.

Other reasons why virulent phage may not select for CRISPR immunity: In the heuristic model considered here and the experiments described in the preceding section, the acquisition of spacers confers immunity to the mobile genetic element from whence the spacers are derived. This may not always be the case. More and more mobile genetic elements are found to encode anti-CRISPR (acr) genes that suppress CRISPR-Cas immune systems through a range of different mechanisms and with often high specificity for a single subtype (107-116). The ability of acrs to bypass immunity of bacteria that are already CRISPR immune varies $(117,118)$, but even the weakest $a c r$ genes characterized to date effectively block the evolution of CRISPR immunity (119).

Other viruses can by-pass CRISPR immunity without a need for acr genes. Some "jumbophages", which are a class of phages with genome sizes that exceed $200 \mathrm{~kb}$, have been reported to form nucleus-like structure during infection (120-122). These structures contain the phage genomes, which shields it from DNA-targeting CRISPR-Cas systems, but not from systems that have RNAtargeting activity, such as Type III-A and VI-A CRISPR-Cas $(123,124)$. This variation in the level of protection explains why in nature spacer acquisition from nucleus-forming jumbophages is detected more frequently for bacteria that carry Type III systems compared to those that carry Type I-E or I-F systems (123). A lack of protection by CRISPR immunity is not limited to jumbophages: E. coli strains carrying Type I-E CRISPR-Cas that were engineered to carry a single targeting spacer against different phages revealed a lack of protection against phages R1-37 (a giant phage) and T4 (125). The ability of phage T4 to by-pass Type I-E CRISPR immunity is at least in part attributable to their genome containing glucosyl-5-hydroxymethylcytosine instead of cytosine (126), and this cytosine modification also confers infectivity to the phage when bacteria have Type II-A CRISPR-based immunity $(126,127)$, but not when they have Type V-A CRISPR-based immunity (126). Type I-E CRISPR-Cas offers protection against phage T7, but only under low phage densities; at high MOIs the cultures were lysed as efficiently as uninduced controls. Efficient protection against T5 was only observed if the CRISPR spacer targeted a pre-early gene (125). Furthermore, a recent study demonstrated that a Type I-F CRISPR-Cas system of Pectobacterium atrosepticum reduced the efficiency of plaquing of two virulent phages $\phi \mathrm{TE}$ and $\phi \mathrm{M} 1$ when the immune system was engineered to carry spacers targeting these phages. Interestingly, CRISPRCas was unable to rescue the host from cell death, hence resulting in an abortive infection (Abi)like phenotype that blocks phage propagation (128). It remains to be determined if and when CRISPR immunity would evolve in bacterial populations exposed to these phages.

These observations are in stark contrast with the high levels of protection against virulent mutants of temperate phage. Examples include high levels of CRISPR-based immunity observed in $P$. aeruginosa strain PA14 against its phage DMS3vir, which we discussed above. Mild or strong overexpression of the Type I-E CRISPR-Cas system of $E$. coli targeting the non-lysogenic mutant $\lambda$ vir provides full immunity, with efficiency of plaquing around $10^{-6}(125,129)$. Similarly, the Type II-A CRISPR-Cas immune system of Streptococcus pyogenes SF370 provides high levels of immunity when expressed in S. aureus RN4220 against the staphylococcal phage $\phi N M 4 \gamma 4$, a lytic mutant of $\phi N M 4$ (44-46) and the Type III-A from S. epidermidis RP62a provides high levels of immunity when expressed in $S$. aureus RN4220 against phage $\phi N M 1 \gamma 6$, a lytic mutant of the temperate phage $\phi N M 1$ (101). Mapping the variability in the levels of protection conferred by CRISPR-Cas immunity using a wider range of CRISPR immune systems and phages will be critical to understand when and where these systems matter. 


\section{Consequences of CRISPR-Cas immunity to the population dynamics, ecology and (co)evolution of bacteria and lytic phage}

In experiments where bacteria evolve high levels of CRISPR-based immunity, three possible outcomes have been observed: the phage (i) are be eliminated in short order, (ii) persist for an extended time in spacer-protospacer arms race but are eventually to be lost, (iii) persist without co-evolution. The first outcome is observed when P. aeruginosa PA14 is infected with DMS3vir $(130,131)$. This is because in this empirical system, the bacteria acquire many different spacers at the population level, which increases the degree of protection since it reduces the evolution and spread of phage that overcome host immunity $(88,130,132)$, which they can do by point mutation (25) or deletion of the target regions on the phage genome (133). A spacer-protospacer arms race is observed when the spacer diversity at the population-level is reduced. In this case, the phage can evolve to overcome host immunity, and hosts, in turn, need to acquire novel spacers to regain immunity. This coevolutionary interaction is observed when S. thermophilus is infected by the lytic phage 2972: bacteria and phage coexist and coevolve for an extended time eventually for the phage to be lost $(73,75,134)$. Phage extinction is in this system due to the arms-race being asymmetrical: acquisition of novel spacers is cost-free for the host (135), whereas accumulating point mutations reduces the fitness of the phage (136). Moreover, the host population gradually increases the diversity of spacers, which makes it harder for the phage to keep up with the host (75). Finally, the phage may continue to be maintained without co-evolution, when bacteria with CRISPR immunity in the population continuously acquire mutations in their CRISPR-Cas immune systems that cause phenotypic reversion to sensitivity (74), or when there is a continuous influx of sensitive bacteria due to immigration (137). While important progress has been made in understanding the consequences of the evolution of CRISPR immunity, most studies have been carried out in highly simplified environments with a single host species infected with a single phage in well-mixed and nutrient-rich broth. Future studies that examine these interactions under more ecologically relevant conditions are desperately needed to understand how CRISPR-Cas systems shape microbial population and evolutionary dynamics in nature.

\section{Conclusion and future directions}

We do not question the validity of the hypothesis that CRISPR-Cas systems can protect bacteria and archaea from infections with deleterious mobile genetic elements. However, what remains unclear is the magnitude of the contribution of these systems to the ecology and evolution of populations of bacteria and archaea and their phage and other mobile genetic elements, collectively MGEs. As outlined above, many key questions remain. First, more experimental and observational studies are needed to understand not only how frequently, but also when, where and why CRISPRCas systems play a role in defense against MGEs (138). Second, it remains unclear how commonly selection mediated by MGEs is responsible for the existence and maintenance of CRISPR-Cas systems in populations of bacteria and archaea, and how this is determined by the type of MGE. Third, while CRISPR-Cas systems clearly spread by HGT, it remains unclear how these genes are able to invade a population from rare, especially if the bacteria or archaea can evolve envelope resistance as well. Finally, our understanding of the ecological and evolutionary consequences of CRISPR-Cas immune responses are limited to in vitro experiments that lack much of the biotic and abiotic complexity of natural environments. Could it be that the biotic and abiotic complexity of the real world, where communities of microbes include multiple species and strains as well as diversity in phage and plasmids, are spatially structured and exist in fluctuating environments are critical to the evolution and maintenance of CRISPR $(50,85,139,140)$ ? Filling these gaps in our 
current understanding of CRISPR ecology and evolution requires interdisciplinary approaches that combine observational studies, mathematical and computer simulation models, as well as population and evolutionary dynamics experiments. The question is how can we do experiments in a way that they would also provide a test of the generality of the hypotheses that are being examined? For that, we would need a diverse array of culturable bacteria and archaea with functional CRISPR-Cas systems and a diverse set of phage and plasmids, which inevitably requires many different research teams to examine these questions. This brings us back to our concern about the dearth of bacteria and archaea phage and plasmid systems amenable for these experimental studies, and the "fishing expedition" dilemma that a quest to find new systems engenders. However, it is always more difficult publishing negative evidence, no matter how informative that evidence would be. We argue that there is a pressing need to publish any negative results of spacer acquisition in response to MGEs, since knowing which culturable bacteria and archaea with functional CRISPR-Cas do and do not acquire spacers and how this depends on the type of infectious DNA will be critical to fully understand the evolutionary ecology of CRISPRCas.

\section{Acknowledgments}

ERW received funding from the Natural Environment Research Council (http://www.nerc.ac.uk) (NE/M018350/1), the Biotechnology and Biological Sciences Research Council (BB/N017412/1), and the European Research Council (https://erc.europa.eu) (ERC-STG-2016-714478 EVOIMMECH). BL was funded by grants from the U.S. National Institutes of General Medical Science GM091875-17 and 1R35 GM136407-01 to (BRL) and the generosity of Emory University. 


\section{References}

1. Ishino Y, Shinagawa H, Makino K, Amemura M, \& Nakata A (1987) Nucleotide sequence of the iap gene, responsible for alkaline phosphatase isozyme conversion in Escherichia coli, and identification of the gene product. J Bacteriol 169(12):5429-5433.

2. Nakata A, Amemura M, \& Makino K (1989) Unusual nucleotide arrangement with repeated sequences in the Escherichia coli K-12 chromosome. J Bacteriol 171(6):35533556.

3. Hermans PW, et al. (1991) Insertion element IS987 from Mycobacterium bovis BCG is located in a hot-spot integration region for insertion elements in Mycobacterium tuberculosis complex strains. Infect Immun 59(8):2695-2705.

4. Mojica FJ, Ferrer C, Juez G, \& Rodriguez-Valera F (1995) Long stretches of short tandem repeats are present in the largest replicons of the Archaea Haloferax mediterranei and Haloferax volcanii and could be involved in replicon partitioning. Mol Microbiol 17(1):8593.

5. Bult CJ, et al. (1996) Complete genome sequence of the methanogenic archaeon, Methanococcus jannaschii. Science 273(5278):1058-1073.

6. Nelson KE, et al. (1999) Evidence for lateral gene transfer between Archaea and bacteria from genome sequence of Thermotoga maritima. Nature 399(6734):323-329.

7. Mojica FJ, Diez-Villasenor C, Soria E, \& Juez G (2000) Biological significance of a family of regularly spaced repeats in the genomes of Archaea, Bacteria and mitochondria. Mol Microbiol 36(1):244-246.

8. Mojica FJ \& Rodriguez-Valera F (2016) The discovery of CRISPR in archaea and bacteria. FEBS J 283(17):3162-3169.

9. Sorek R, Kunin V, \& Hugenholtz P (2008) CRISPR--a widespread system that provides acquired resistance against phages in bacteria and archaea. Nat Rev Microbiol 6(3):181186.

10. Pourcel C, Salvignol G, \& Vergnaud G (2005) CRISPR elements in Yersinia pestis acquire new repeats by preferential uptake of bacteriophage DNA, and provide additional tools for evolutionary studies. Microbiology 151(Pt 3):653-663.

11. Makarova KS, Grishin NV, Shabalina SA, Wolf YI, \& Koonin EV (2006) A putative RNAinterference-based immune system in prokaryotes: computational analysis of the predicted enzymatic machinery, functional analogies with eukaryotic RNAi, and hypothetical mechanisms of action. Biol Direct 1:7.

12. Makarova KS, et al. (2015) An updated evolutionary classification of CRISPR-Cas systems. Nat Rev Microbiol 13(11):722-736.

13. Koonin EV, Makarova KS, \& Wolf YI (2017) Evolutionary Genomics of Defense Systems in Archaea and Bacteria. Annu Rev Microbiol 71:233-261.

14. Makarova KS, et al. (2020) Evolutionary classification of CRISPR-Cas systems: a burst of class 2 and derived variants. Nat Rev Microbiol 18(2):67-83. 
15. Jansen R, Embden JD, Gaastra W, \& Schouls LM (2002) Identification of genes that are associated with DNA repeats in prokaryotes. Mol Microbiol 43(6):1565-1575.

16. Makarova KS, Aravind L, Grishin NV, Rogozin IB, \& Koonin EV (2002) A DNA repair system specific for thermophilic Archaea and bacteria predicted by genomic context analysis. Nucleic Acids Res 30(2):482-496.

17. Haft DH, Selengut J, Mongodin EF, \& Nelson KE (2005) A guild of 45 CRISPR-associated (Cas) protein families and multiple CRISPR/Cas subtypes exist in prokaryotic genomes. PLoS Comput Biol 1(6):e60.

18. Makarova KS \& Koonin EV (2015) Annotation and Classification of CRISPR-Cas Systems. Methods Mol Biol 1311:47-75.

19. Shmakov SA, et al. (2019) Systematic prediction of functionally linked genes in bacterial and archaeal genomes. Nat Protoc 14(10):3013-3031.

20. Shmakov S, et al. (2017) Diversity and evolution of class 2 CRISPR-Cas systems. Nat Rev Microbiol 15(3):169-182.

21. Koonin EV \& Makarova KS (2019) Origins and evolution of CRISPR-Cas systems. Philos Trans R Soc Lond B Biol Sci 374(1772):20180087.

22. Mojica FJ, Diez-Villasenor C, Garcia-Martinez J, \& Soria E (2005) Intervening sequences of regularly spaced prokaryotic repeats derive from foreign genetic elements. $J$ Mol Evol 60(2):174-182.

23. Bolotin A, Quinquis B, Sorokin A, \& Ehrlich SD (2005) Clustered regularly interspaced short palindrome repeats (CRISPRs) have spacers of extrachromosomal origin. Microbiology 151(Pt 8):2551-2561.

24. Barrangou R, et al. (2007) CRISPR provides acquired resistance against viruses in prokaryotes. Science 315(5819):1709-1712.

25. Deveau H, et al. (2008) Phage response to CRISPR-Encoded resistance in Streptococcus thermophilus. Journal of Bacteriology 190(4):1390-1400.

26. Iranzo J, Lobkovsky AE, Wolf YI, \& Koonin EV (2013) Evolutionary dynamics of the prokaryotic adaptive immunity system CRISPR-Cas in an explicit ecological context. $J$ Bacteriol 195(17):3834-3844.

27. Childs LM, Held NL, Young MJ, Whitaker RJ, \& Weitz JS (2012) Multiscale model of CRISPR-induced coevolutionary dynamics: diversification at the interface of Lamarck and Darwin. Evolution 66(7):2015-2029.

28. Childs LM, England WE, Young MJ, Weitz JS, \& Whitaker RJ (2014) CRISPR-induced distributed immunity in microbial populations. PLoS One 9(7):e101710.

29. Tyson GW \& Banfield JF (2008) Rapidly evolving CRISPRs implicated in acquired resistance of microorganisms to viruses. Environ Microbiol 10(1):200-207.

30. Andersson AF \& Banfield JF (2008) Virus population dynamics and acquired virus resistance in natural microbial communities. Science 320(5879):1047-1050. 
31. Pride DT, et al. (2011) Analysis of streptococcal CRISPRs from human saliva reveals substantial sequence diversity within and between subjects over time. Genome Res 21(1):126-136.

32. Laanto E, Hoikkala V, Ravantti J, \& Sundberg L-R (2017) Long-term genomic coevolution of host-parasite interaction in the natural environment. Nature communications 8(1):111.

33. Pauly MD, Bautista MA, Black JA, \& Whitaker RJ (2019) Diversified local CRISPR-Cas immunity to viruses of Sulfolobus islandicus. Philos Trans $R$ Soc Lond B Biol Sci 374(1772):20180093.

34. Bautista MA, Black JA, Youngblut ND, \& Whitaker RJ (2017) Differentiation and Structure in Sulfolobus islandicus Rod-Shaped Virus Populations. Viruses 9(5).

35. Held NL \& Whitaker RJ (2009) Viral biogeography revealed by signatures in Sulfolobus islandicus genomes. Environ Microbiol 11(2):457-466.

36. Held NL, Herrera A, Cadillo-Quiroz H, \& Whitaker RJ (2010) CRISPR associated diversity within a population of Sulfolobus islandicus. PLoS One 5(9).

37. van der Ploeg JR (2009) Analysis of CRISPR in Streptococcus mutans suggests frequent occurrence of acquired immunity against infection by M102-like bacteriophages. Microbiology 155(Pt 6):1966-1976.

38. Heidelberg JF, Nelson WC, Schoenfeld T, \& Bhaya D (2009) Germ warfare in a microbial mat community: CRISPRs provide insights into the co-evolution of host and viral genomes. PLoS One 4(1):e4169.

39. Skennerton CT, Imelfort M, \& Tyson GW (2013) Crass: identification and reconstruction of CRISPR from unassembled metagenomic data. Nucleic Acids Res 41(10):e105.

40. Shmakov SA, et al. (2017) The CRISPR Spacer Space Is Dominated by Sequences from Species-Specific Mobilomes. MBio 8(5).

41. Swarts DC, Mosterd C, van Passel MW, \& Brouns SJ (2012) CRISPR interference directs strand specific spacer acquisition. PLoS One 7(4):e35888.

42. Datsenko KA, et al. (2012) Molecular memory of prior infections activates the CRISPR/Cas adaptive bacterial immunity system. Nat Commun 3:945.

43. Yosef I, Goren MG, \& Qimron U (2012) Proteins and DNA elements essential for the CRISPR adaptation process in Escherichia coli. Nucleic Acids Res 40(12):5569-5576.

44. Heler R, et al. (2015) Cas9 specifies functional viral targets during CRISPR-Cas adaptation. Nature 519(7542):199-202.

45. Modell JW, Jiang WY, \& Marraffini LA (2017) CRISPR-Cas systems exploit viral DNA injection to establish and maintain adaptive immunity. Nature 544(7648):101-+.

46. Nussenzweig PM, McGinn J, \& Marraffini LA (2019) Cas9 Cleavage of Viral Genomes Primes the Acquisition of New Immunological Memories. Cell Host Microbe 26(4):515+ .

47. Heler R, Wright AV, Vucelja M, Doudna JA, \& Marraffini LA (2019) Spacer Acquisition Rates Determine the Immunological Diversity of the Type II CRISPR-Cas Immune Response. Cell Host Microbe 25(2):242-249 e243. 
48. Richter C, et al. (2014) Priming in the Type I-F CRISPR-Cas system triggers strandindependent spacer acquisition, bi-directionally from the primed protospacer. Nucleic Acids Res 42(13):8516-8526.

49. Cady KC, Bondy-Denomy J, Heussler GE, Davidson AR, \& O'Toole GA (2012) The CRISPR/Cas adaptive immune system of Pseudomonas aeruginosa mediates resistance to naturally occurring and engineered phages. J Bacteriol 194(21):5728-5738.

50. Westra ER, et al. (2015) Parasite exposure drives selective evolution of constitutive versus inducible defense. Curr Biol 25(8):1043-1049.

51. Cornuault JK, et al. (2019) The enemy from within: a prophage of Roseburia intestinalis systematically turns lytic in the mouse gut, driving bacterial adaptation by CRISPR spacer acquisition. ISME J.

52. Erdmann S \& Garrett RA (2012) Selective and hyperactive uptake of foreign DNA by adaptive immune systems of an archaeon via two distinct mechanisms. Mol Microbiol 85(6):1044-1056.

53. Jackson SA, et al. (2017) CRISPR-Cas: Adapting to change. Science 356(6333).

54. Pawluk A, Davidson AR, \& Maxwell KL (2018) Anti-CRISPR: discovery, mechanism and function. Nat Rev Microbiol 16(1):12-17.

55. Oliveira PH, Touchon M, \& Rocha EP (2014) The interplay of restriction-modification systems with mobile genetic elements and their prokaryotic hosts. Nucleic Acids Res 42(16):10618-10631.

56. Palmer KL \& Gilmore MS (2010) Multidrug-resistant enterococci lack CRISPR-cas. MBio 1(4).

57. O'Meara D \& Nunney L (2019) A phylogenetic test of the role of CRISPR-Cas in limiting plasmid acquisition and prophage integration in bacteria. Plasmid 104:102418.

58. Gophna U, et al. (2015) No evidence of inhibition of horizontal gene transfer by CRISPRCas on evolutionary timescales. ISME J 9(9):2021-2027.

59. Touchon M, et al. (2012) Antibiotic resistance plasmids spread among natural isolates of Escherichia coli in spite of CRISPR elements. Microbiology 158(12):2997-3004.

60. England WE, Kim T, \& Whitaker RJ (2018) Metapopulation Structure of CRISPR-Cas Immunity in Pseudomonas aeruginosa and Its Viruses. mSystems 3(5).

61. Staals RH, et al. (2016) Interference-driven spacer acquisition is dominant over naive and primed adaptation in a native CRISPR-Cas system. Nat Commun 7:12853.

62. Amlinger L, Hoekzema M, Wagner EGH, Koskiniemi S, \& Lundgren M (2017) Fluorescent CRISPR Adaptation Reporter for rapid quantification of spacer acquisition. Sci Rep 7(1):10392.

63. Diez-Villasenor C, Guzman NM, Almendros C, Garcia-Martinez J, \& Mojica FJ (2013) CRISPR-spacer integration reporter plasmids reveal distinct genuine acquisition specificities among CRISPR-Cas I-E variants of Escherichia coli. RNA Biol 10(5):792-802.

64. Kieper SN, et al. (2018) Cas4 Facilitates PAM-Compatible Spacer Selection during CRISPR Adaptation. Cell Rep 22(13):3377-3384. 
65. McKenzie RE, Almendros C, Vink JNA, \& Brouns SJJ (2019) Using CAPTURE to detect spacer acquisition in native CRISPR arrays. Nat Protoc 14(3):976-990.

66. Schmidt F, Cherepkova MY, \& Platt RJ (2018) Transcriptional recording by CRISPR spacer acquisition from RNA. Nature 562(7727):380-385.

67. Mohanraju P, et al. (2016) Diverse evolutionary roots and mechanistic variations of the CRISPR-Cas systems. Science 353(6299):aad5147.

68. Westra ER, Dowling AJ, Broniewski JM, \& van Houte S (2016) Evolution and Ecology of CRISPR. Annual Review of Ecology, Evolution, and Systematics, Vol 47 47:307-331.

69. Touchon M \& Rocha EP (2010) The small, slow and specialized CRISPR and anti-CRISPR of Escherichia and Salmonella. PLoS One 5(6):e11126.

70. Bernheim A, Bikard D, Touchon M, \& Rocha EPC (2020) Atypical organizations and epistatic interactions of CRISPRs and cas clusters in genomes and their mobile genetic elements. Nucleic Acids Res 48(2):748-760.

71. Gurney J, Pleska M, \& Levin BR (2019) Why put up with immunity when there is resistance: an excursion into the population and evolutionary dynamics of restrictionmodification and CRISPR-Cas. Philos Trans R Soc Lond B Biol Sci 374(1772):20180096.

72. Horvath P, et al. (2008) Diversity, activity, and evolution of CRISPR loci in Streptococcus thermophilus. J Bacteriol 190(4):1401-1412.

73. Paez-Espino D, et al. (2015) CRISPR immunity drives rapid phage genome evolution in Streptococcus thermophilus. MBio 6(2).

74. Weissman J, et al. (2018) Immune loss as a driver of coexistence during host-phage coevolution. ISME:1-13.

75. Common J, Morley D, Westra ER, \& van Houte S (2019) CRISPR-Cas immunity leads to a coevolutionary arms race between Streptococcus thermophilus and lytic phage. Philos Trans $R$ Soc Lond B Biol Sci 374(1772):20180098.

76. McDonnell B, Mahony J, Hanemaaijer L, Kouwen T, \& van Sinderen D (2018) Generation of Bacteriophage-Insensitive Mutants of Streptococcus thermophilus via an Antisense RNA CRISPR-Cas Silencing Approach. Appl Environ Microbiol 84(4).

77. Labrie SJ, et al. (2019) A mutation in the methionine aminopeptidase gene provides phage resistance in Streptococcus thermophilus. Sci Rep 9(1):13816.

78. Chevallereau A, Meaden S, van Houte S, Westra ER, \& Rollie C (2019) The effect of bacterial mutation rate on the evolution of CRISPR-Cas adaptive immunity. Philos Trans R Soc Lond B Biol Sci 374(1772):20180094.

79. Nicholson TJ, et al. (2019) Bioinformatic evidence of widespread priming in type I and II CRISPR-Cas systems. RNA Biol 16(4):566-576.

80. Musharova O, et al. (2019) Systematic analysis of Type I-E Escherichia coli CRISPR-Cas PAM sequences ability to promote interference and primed adaptation. Mol Microbiol 111(6):1558-1570.

81. Xue C, et al. (2015) CRISPR interference and priming varies with individual spacer sequences. Nucleic Acids Res 43(22):10831-10847. 
82. Musharova O, et al. (2018) Avoidance of Trinucleotide Corresponding to Consensus Protospacer Adjacent Motif Controls the Efficiency of Prespacer Selection during Primed Adaptation. MBio 9(6).

83. Hynes AP, Villion M, \& Moineau S (2014) Adaptation in bacterial CRISPR-Cas immunity can be driven by defective phages. Nat Commun 5:4399.

84. Dupuis ME, Villion M, Magadan AH, \& Moineau S (2013) CRISPR-Cas and restrictionmodification systems are compatible and increase phage resistance. Nat Commun 4:2087.

85. Alseth EO, et al. (2019) Bacterial biodiversity drives the evolution of CRISPR-based phage resistance. Nature 574(7779):549-552.

86. van Houte S, Buckling A, \& Westra ER (2016) Evolutionary Ecology of Prokaryotic Immune Mechanisms. Microbiol Mol Biol Rev 80(3):745-763.

87. Stewart FM \& Levin BR (1984) The population biology of bacterial viruses: why be temperate. Theoretical population biology 26(1):93-117.

88. Rollie C, et al. (2020) Targeting of temperate phages drives loss of type I CRISPR-Cas systems. Nature 578(7793):149-153.

89. Taylor VL, Fitzpatrick AD, Islam Z, \& Maxwell KL (2019) The Diverse Impacts of Phage Morons on Bacterial Fitness and Virulence. Adv Virus Res 103:1-31.

90. Harrison E \& Brockhurst MA (2017) Ecological and Evolutionary Benefits of Temperate Phage: What Does or Doesn't Kill You Makes You Stronger. Bioessays 39(12).

91. Gloag ES, et al. (2019) Pseudomonas aeruginosa Interstrain Dynamics and Selection of Hyperbiofilm Mutants during a Chronic Infection. MBio 10(4).

92. Vercoe RB, et al. (2013) Cytotoxic chromosomal targeting by CRISPR/Cas systems can reshape bacterial genomes and expel or remodel pathogenicity islands. PLoS Genet 9(4):e1003454.

93. Edgar R \& Qimron U (2010) The Escherichia coli CRISPR system protects from lambda lysogenization, lysogens, and prophage induction. J Bacteriol 192(23):6291-6294.

94. Citorik RJ, Mimee M, \& Lu TK (2014) Sequence-specific antimicrobials using efficiently delivered RNA-guided nucleases. Nat Biotechnol 32(11):1141-1145.

95. Ramachandran G \& Bikard D (2019) Editing the microbiome the CRISPR way. Philos Trans R Soc Lond B Biol Sci 374(1772):20180103.

96. Bikard D \& Barrangou R (2017) Using CRISPR-Cas systems as antimicrobials. Curr Opin Microbiol 37:155-160.

97. Cui L \& Bikard D (2016) Consequences of Cas9 cleavage in the chromosome of Escherichia coli. Nucleic Acids Res 44(9):4243-4251.

98. Pursey E, Sunderhauf D, Gaze WH, Westra ER, \& van Houte S (2018) CRISPR-Cas antimicrobials: Challenges and future prospects. PLoS Pathog 14(6):e1006990.

99. Gomaa AA, et al. (2014) Programmable removal of bacterial strains by use of genometargeting CRISPR-Cas systems. MBio 5(1):e00928-00913. 
100. Goldberg GW, et al. (2018) Incomplete prophage tolerance by type III-A CRISPR-Cas systems reduces the fitness of lysogenic hosts. Nat Commun 9(1):61.

101. Goldberg GW, Jiang W, Bikard D, \& Marraffini LA (2014) Conditional tolerance of temperate phages via transcription-dependent CRISPR-Cas targeting. Nature 514(7524):633-637.

102. Stewart FM \& Levin BR (1977) The population biology of bacterial plasmids: a priori conditions for the existence of conjugationally transmitted factors. Genetics 87:209-228.

103. Gandon S \& Vale PF (2014) The evolution of resistance against good and bad infections. J Evol Biol 27(2):303-312.

104. Fineran PC, et al. (2014) Degenerate target sites mediate rapid primed CRISPR adaptation. P Natl Acad Sci USA 111(16):E1629-E1638.

105. Jiang W, et al. (2013) Dealing with the evolutionary downside of CRISPR immunity: bacteria and beneficial plasmids. PLoS Genet 9(9):e1003844.

106. van Sluijs L, et al. (2019) Addiction systems antagonize bacterial adaptive immunity. FEMS Microbiol Lett.

107. Bondy-Denomy J, Pawluk A, Maxwell KL, \& Davidson AR (2013) Bacteriophage genes that inactivate the CRISPR/Cas bacterial immune system. Nature 493(7432):429-432.

108. Hynes AP, et al. (2018) Widespread anti-CRISPR proteins in virulent bacteriophages inhibit a range of Cas9 proteins. Nature Communications 9.

109. Hynes AP, et al. (2017) An anti-CRISPR from a virulent streptococcal phage inhibits Streptococcus pyogenes Cas9. Nature Microbiology 2(10):1374-1380.

110. Athukoralage JS, et al. (2020) An anti-CRISPR viral ring nuclease subverts type III CRISPR immunity. Nature 577(7791):572-575.

111. Bhoobalan-Chitty Y, Johansen TB, Di Cianni N, \& Peng X (2019) Inhibition of Type III CRISPR-Cas Immunity by an Archaeal Virus-Encoded Anti-CRISPR Protein. Cell 179(2):448-458 e411.

112. He F, et al. (2018) Anti-CRISPR proteins encoded by archaeal lytic viruses inhibit subtype I-D immunity. Nat Microbiol 3(4):461-469.

113. Watters KE, Fellmann C, Bai HB, Ren SM, \& Doudna JA (2018) Systematic discovery of natural CRISPR-Cas12a inhibitors. Science 362(6411):236-239.

114. Marino ND, et al. (2018) Discovery of widespread type I and type V CRISPR-Cas inhibitors. Science 362(6411):240-242.

115. Pawluk A, et al. (2016) Naturally Occurring Off-Switches for CRISPR-Cas9. Cell 167(7):1829-1838 e1829.

116. Pawluk A, Bondy-Denomy J, Cheung VH, Maxwell KL, \& Davidson AR (2014) A new group of phage anti-CRISPR genes inhibits the type I-E CRISPR-Cas system of Pseudomonas aeruginosa. MBio 5(2):e00896.

117. Landsberger M, et al. (2018) Anti-CRISPR Phages Cooperate to Overcome CRISPR-Cas Immunity. Cell. 
118. Borges AL, et al. (2018) Bacteriophage Cooperation Suppresses CRISPR-Cas3 and Cas9 Immunity. Cell 174(4):917-+.

119. Chevallereau A, et al. (2020) Exploitation of the cooperative behaviours of anti-CRISPR phages. Cell Host Microbe, in press. Cell Host Microbe in press.

120. Chaikeeratisak V, et al. (2019) Viral Capsid Trafficking along Treadmilling Tubulin Filaments in Bacteria. Cell 177(7):1771-+.

121. Chaikeeratisak V, et al. (2017) Assembly of a nucleus-like structure during viral replication in bacteria. Science 355(6321):194-197.

122. Chaikeeratisak V, et al. (2017) The Phage Nucleus and Tubulin Spindle Are Conserved among Large Pseudomonas Phages. Cell Reports 20(7):1563-1571.

123. Malone LM, et al. (2019) A jumbo phage that forms a nucleus-like structure evades CRISPR-Cas DNA targeting but is vulnerable to type III RNA-based immunity. Nat Microbiol.

124. Mendoza SD, et al. (2019) A bacteriophage nucleus-like compartment shields DNA from CRISPR nucleases. Nature.

125. Strotskaya A, et al. (2017) The action of Escherichia coli CRISPR-Cas system on lytic bacteriophages with different lifestyles and development strategies. Nucleic Acids Research 45(4):1946-1957.

126. Vlot M, et al. (2018) Bacteriophage DNA glucosylation impairs target DNA binding by type I and II but not by type V CRISPR-Cas effector complexes. Nucleic Acids Research 46(2):873-885.

127. Bryson AL, et al. (2015) Covalent Modification of Bacteriophage T4 DNA Inhibits CRISPR-Cas9. Mbio 6(3).

128. Watson BNJ, et al. (2019) Type I-F CRISPR-Cas resistance against virulent phages results in abortive infection and provides population-level immunity. Nat Commun 10(1):5526.

129. Brouns SJJ, et al. (2008) Small CRISPR RNAs guide antiviral defense in prokaryotes. Science 321(5891):960-964.

130. van Houte S, et al. (2016) The diversity-generating benefits of a prokaryotic adaptive immune system. Nature 532(7599):385-388.

131. Morley D, Broniewski JM, Westra ER, Buckling A, \& van Houte S (2017) Host diversity limits the evolution of parasite local adaptation. Mol Ecol 26(7):1756-1763.

132. Chabas H, et al. (2018) Evolutionary emergence of infectious diseases in heterogeneous host populations. Plos Biol 16(9).

133. Watson BNJ, et al. (2019) Different genetic and morphological outcomes for phages targeted by single or multiple CRISPR-Cas spacers. Philos T R Soc B 374(1772).

134. Paez-Espino D, et al. (2013) Strong bias in the bacterial CRISPR elements that confer immunity to phage. Nat Commun 4:1430.

135. Vale PF, et al. (2015) Costs of CRISPR-Cas-mediated resistance in Streptococcus thermophilus. Proc Biol Sci 282(1812):20151270. 
136. Chabas H, et al. (2019) Variability in the durability of CRISPR-Cas immunity. Philos Trans R Soc Lond B Biol Sci 374(1772):20180097.

137. Chabas H, van Houte S, Hoyland-Kroghsbo NM, Buckling A, \& Westra ER (2016) Immigration of susceptible hosts triggers the evolution of alternative parasite defence strategies. Proc Biol Sci 283(1837).

138. Weissman JL, Laljani RMR, Fagan WF, \& Johnson PLF (2019) Visualization and prediction of CRISPR incidence in microbial trait-space to identify drivers of antiviral immune strategy. ISME J 13(10):2589-2602.

139. Broniewski JM, Meaden S, Paterson S, Buckling A, \& Westra ER (2020) The effect of phage genetic diversity on bacterial resistance evolution. ISME J 14(3):828-836.

140. Weissman JL, Fagan WF, \& Johnson PLF (2018) Selective Maintenance of Multiple CRISPR Arrays Across Prokaryotes. CRISPR J 1:405-413. 


\title{
How important is CRISPR-Cas for protecting natural populations of bacteria against infections by mobile genetic elements?
}

\author{
Edze Westra and Bruce Levin
}

\section{Supplemental Material. A theoretical consideration of the population and evolutionary dynamics of CRISPR-Cas mediated immunity}

As considered in the body of this perspective, CRISPR-Cas can provide bacteria protection against infections by mobile genetic elements of three major sources, lytic (virulent) phage, temperate phage, and self-transmissible plasmids. In this supplemental material, we use simple mathematical and computer simulation models to elucidate the a priori conditions under which these three types infectious mobile genetic elements will select for (i) CRISPR-Cas mediated immunity in populations with functional CRISPR-Cas systems, CRISPR ${ }^{+}$, and (ii) the ascent of $\mathrm{CRISPR}^{+}$ bacteria in populations without functional CRISPR-Cas systems, CRISPR-. A particular focus of our analysis of the properties of these models are "invasion conditions"; the conditions under which selection mediated by mobile genetic elements will lead to increases in the frequency of CRISPR-Cas immune populations when they are initially rare. As in the body of this report, we separately consider these invasion conditions for populations with functional CRISPR-Cas systems, $\mathrm{CRISPR}^{+}$and populations without these adaptive immune systems, CRISPR-

For all of these models, we assume the populations are maintained in continuous (chemostat) culture. A limiting resource, $\mathrm{r} \mu \mathrm{g} / \mathrm{ml}$ from a reservoir where it is present at a concentration $\mathrm{R} \mu \mathrm{g} / \mathrm{ml}$ enters a habitat of unit volume at a rate $\mathrm{w}$ per hour, which is the same rate at which excess resources, bacteria, and free phage are removed. The rate of growth of the bacteria of type $\mathrm{i}$ is directly proportional to its maximum growth $\mathrm{V}_{\mathrm{i}}$ per cell per hour and hyperbolic function of the concentration of the resource (141).

$$
Z_{i}(r)=v_{i} \cdot \frac{r}{(r+k)}
$$

The parameter, $k$, the Monod constant, is the concentration of the limiting resource, where the rate of growth of the population is half its maximum value. As in (142), we assume the limiting resource is consumed at a rate proportional to the growth rate of those bacteria, $Z_{i}(r)$, and the amount of resource required to produce a new cell is e $\mu \mathrm{g} / \mathrm{ml}$.

The properties of these models were analyzed numerically with Berkeley Madonna. For copies of these programs and instructions for their use, write to blevin@emory.edu. The models used for these numerical analyses are generic and chosen to illustrate the conditions under which selection mediated by phage and plasmids will favor the evolution of CRISPR-Cas immunity. However, the growth rates, phage infection and lysogeny rates, and plasmid transfer rates are in the ranges estimated in the cited experimental studies.

\section{The population dynamics of lytic phage and bacteria with and without CRISPR-Cas immunity}

The Model: In this model, depicted in Figure S1, there is a single population of lytic phage, V, and two types of bacteria: those that are CRISPR ${ }^{+}$(i.e. carry a functional CRISPR-Cas system) and those that are CRISPR- (i.e. lack a functional CRISPR-Cas system). CRISPR- bacteria can exist in two states; they can either be sensitive to the phage or they can have surface resistance, respectively $\mathrm{S}$ and SR. CRISPR ${ }^{+}$populations can exist in three states: one sensitive to the phage, $\mathrm{C}$, one with 
surface resistance, CR, and one that is CRISPR immune, CI. The resistant cells, SR and CR, are refractory to the phage, while the CRISPR immune population can be infected by the phage, but the infecting phage are lost. The variables V, S, SR, C, CR, and CI are both the designations and densities of these populations, particles, in cells per ml. In Table S1, we list the variables and parameters of this model, their dimensions and the range of parameter values used.

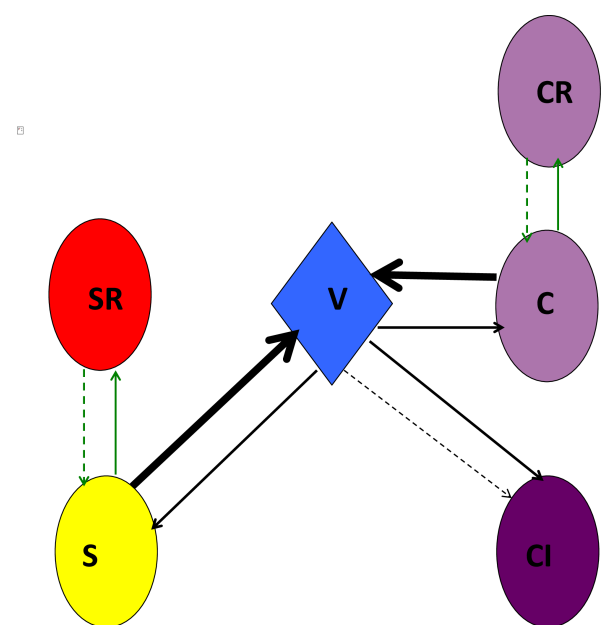

Figure: S1 Lytic phage model: V - free phage, S - CRISPR ${ }^{-}$sensitive bacteria, SR - CRISPR ${ }^{-}$resistant (refractory) bacteria, C - CRISPR ${ }^{+}$phage sensitive bacteria, CR - CRISPR ${ }^{+}$resistant (refractory) bacteria, CI - CRISPR ${ }^{+}$immune bacteria. The thin black arrows indicate infection and thick black arrow lytic production of phage. The thin green solid and dotted lines designate transitions between states due to mutation or phenotypic processes, respectively, the generation and loss of resistance and CRISPR-Cas mediated immunity.

In the absence of phage, bacteria grow at maximum rates, $v_{S}, v_{S R}, v_{C}, v_{R}$ and $v_{C I}$ per cell per hour. The phage adsorb to the bacteria at a rate proportional to the product of their densities and a rate parameter, $\delta$ cell $\mathrm{x} \mathrm{ml} /$ hour (143). If the hosts are sensitive to the phage, $\mathrm{S}$ or $\mathrm{C}$, upon infection $\beta$ phage particles per cell, the burst size, are produced and the infected host cells are removed from the population. Phage infecting $\mathrm{CRISPR}^{+}$immune cells, CI, are lost and removed from the population. A fraction, $\mathrm{x}(0 \leq \mathrm{x} \leq 1)$ of the adsorptions of phage $\mathrm{V}$ to sensitive $\mathrm{CRISPR}^{+}$cells, $\mathrm{C}$, produce immune cells CI (71). By mutation at a rate $\mu_{\mathrm{SR}}$ per cell per hour, sensitive cells generate resistant mutants, $\mathrm{S} \rightarrow \mathrm{SR}$, and $\mathrm{C} \rightarrow \mathrm{CR}$. As in (144) we assume that either by mutation or phenotypic processes, at a rate $\mu_{\mathrm{RS}}$ per cell per hour resistant cells become susceptible, $\mathrm{SR} \rightarrow \mathrm{S}$, and $\mathrm{CR} \rightarrow \mathrm{C}$. With these definitions, the rates of change in the densities of the bacteria and phage and concentration of resources is given by the following set of coupled differential equations. 


$$
\begin{aligned}
& \frac{d r}{d t}=w \cdot(R R-r)-e \cdot \psi(r) \cdot\left(v_{S} \cdot S+v_{S R} \cdot S R+v_{C} \cdot C+v_{C R} \cdot C R+v_{C I} \cdot C I\right) \\
& \frac{d S}{d t}=v_{S} \cdot S \cdot \psi(r)-\delta \cdot V \cdot S+\mu_{R S} \cdot S R-\mu_{S R} \cdot S-w \cdot S \\
& \frac{d S R}{d t}=v_{S R} \cdot S R \cdot \psi(r)+\mu_{S R} \cdot S-\mu_{R S} \cdot S R-w \cdot S R \\
& \frac{d C}{d t}=v_{C} \cdot C \cdot \psi(r)-\delta \cdot V \cdot C-\mu_{S R} \cdot C+\mu_{R S} \cdot C R-w \cdot C \\
& \frac{d C R}{d t}=v_{C R} \cdot C R \cdot \psi(r)+\mu_{S R} \cdot C-\mu_{R S} \cdot C R-w \cdot C R \\
& \frac{d C I}{d t}=v_{C I} \cdot C I \cdot \psi(r)+x \cdot \delta \cdot V \cdot C-w \cdot C I \\
& \frac{d V}{d t}=\delta \cdot V \cdot S \cdot(\beta-1)+\delta \cdot V \cdot C \cdot(1-x) \cdot(\beta-1)-\delta \cdot V \cdot C I-w \cdot V \\
& w h e r e \quad \psi(r)=\frac{r}{(r+k)}
\end{aligned}
$$

\section{1- The evolution of CRISPR immunity and surface resistance in CRISPR ${ }^{+}$populations}

When sensitive populations of CRISPR- bacteria, S, are confronted with phage, resistant mutants, $\mathrm{SR}$, will ascend and become the dominant bacterial population. In $\mathrm{CRISPR}^{+}$populations this dominant population will be either resistant bacteria, CR, or immune cells, CI, which are produced by the acquisition of a spacer from the phage. Whether resistant mutants or CRISPR-Cas immune cells will dominate depends on the rate of mutation to resistance, $\mathrm{S} \rightarrow \mathrm{SR}$ and $\mathrm{C} \rightarrow \mathrm{CR}$, and the rate of spacer acquisition, $\mathrm{C} \rightarrow \mathrm{CI}$.

To illustrate this, we consider a continuous culture community of sensitive bacteria of density $\mathrm{N}$ cells per $\mathrm{ml}$ at equilibrium with lytic phage in a habitat where resources are sufficient for the rates of growth to be at their maximum. Under these conditions, the densities of the phage and bacteria populations would be,

$$
V^{*}=\frac{(v-w)}{\delta} \text { and } N^{*}=\frac{w}{\delta \cdot \beta}
$$

Where $V^{*}$ is the equilibrium density of the phage and $N^{*}$ the equilibrium density of the bacteria. For example, if the maximum growth rate of the bacteria, $v=0.7$ per hour, the adsorption rate constant, $\delta=10^{-7}$, the burst size $\beta=50$, and the flow rate $w=0.1$ per hour, the equilibrium densities of bacteria and phage would be, respectively $\mathrm{N}^{*}=2.0 \times 10^{4}$ and

$\mathrm{V}^{*}=6.0 \times 10^{6}$.

For a population of CRISPR ${ }^{+}$sensitive bacteria at equilibrium with phage, $\mathrm{C}^{*}$ and $\mathrm{V}^{*}$, whether resistant, CR, or immune CI cells will appear first will depend on the rate of mutation to resistance, $\mu_{\mathrm{SR}}$, the likelihood of the bacteria picking up a spacer, the parameters $\delta$ and $\mathrm{x}$ and the total number of bacteria, $\mathrm{C}^{*} \bullet \mathrm{Vol}$. If $\mu_{\mathrm{SR}} \bullet \mathrm{C}^{*} \bullet \mathrm{Vol}>\mathrm{x} \bullet \delta \bullet \mathrm{V}^{*} \bullet \mathrm{C}^{*} \bullet \mathrm{Vol}$, resistance will more likely appear before 
CRISPR immunity. In general, for CRISPR-Cas immune cells to be generated before resistant ones,

$$
x \cdot \delta \cdot V^{*} \cdot C^{*}>\mu_{S R} \cdot C^{*} \text { or } x>\frac{\mu_{S R}}{\delta \cdot V^{*}}
$$

For example, if the mutation rate to resistance is $\mu_{\mathrm{SR}}=10^{-8}$, with $\delta=10^{-7}$ and $\mathrm{V}^{*}=6 \times 10^{6}$, for CI to appear before $\mathrm{CR}$, the probability of acquiring a spacer upon infection, $\mathrm{x}$ has to exceed $1.67 \times 10^{-}$ ${ }^{8}$. If $\mathrm{x}=1.67 \times 10^{-7}$, the probability of acquiring a spacer is $10 \mathrm{X}$ as great as that of generating a resistant mutant.

(i) Establishment of resistance and immunity in a CRISPR+ population: In Figure S2, we consider the establishment of immune and resistant bacteria, respectively $\mathrm{CI}$ and $\mathrm{CR}$, in a phage sensitive $\mathrm{CRISPR}^{+}$population, $\mathrm{C}$, initially at equilibrium with the phage. For these simulations, we use a semi-stochastic version of this model where the generation of mutants or the acquisition of spacers are determined by a Monte Carlo process, with the rest of the transitions between states being deterministic. Consequently, although all of the runs were started with the same conditions, the dynamics differed because mutation and the acquisition of spacers are stochastic processes. In Figure S2A, B, and C we present runs with different outcomes: A where the immune cells become the dominant population, $\mathrm{B}$ where the resistant cells become the dominant population, and $\mathrm{C}$ where the resistant cells become the dominant population but a high density of immune cells are maintained.

For a more comprehensive perspective of when these different outcomes are anticipated and the likelihood of their occurrence, we use a Monte Carlo simulation to determine the average density of immune and resistant cells at different times for 100 runs with these parameters (Figures 1A and S2D). In the absence of mutation to resistance, $\mu_{\mathrm{SR}}=\mu_{\mathrm{RS}}=0$, within short order immune cells, $\mathrm{CI}$, evolve and dominate the $\mathrm{CRISPR}^{+}$population. When resistance and immune cells are equally likely to be generated, both are equally likely evolve to ascend to dominate the bacterial population. If, as in Figure S2D, CRISPR-Cas immunity is more likely to be generated than envelope resistance, immune cells evolve to dominate.

(ii) Establishment of CRISPR ${ }^{+}$bacteria in CRISPR ${ }^{-}$populations: In Figure S3A-C, we consider the dynamics of the changes in the densities of the different populations of bacteria, S, SR, C, CI and $\mathrm{CR}$, the phage $\mathrm{V}$, and the concentration of the resource, $r$, for situations where resistance can be generated $\mu_{\mathrm{SR}}=\mu_{\mathrm{RS}}=10^{-8}$. In these simulations, the sensitive populations are initially at equilibrium with the phage, $\mathrm{V}=6 \times 10^{6}$, and the density of $\mathrm{CRISPR}^{+}$is around $10 \%$ of the total population, respectively $\mathrm{C}=2 \times 10^{3}$ and $\mathrm{S}=1.8 \times 10^{4}$ cells $\mathrm{ml}^{-1}$. CRISPR-, $\mathrm{SR}$, or CRISPR ${ }^{+}, \mathrm{CR}$, cells can emerge and ascend to dominate the population (Figure S3A and B, respectively). CRISPR ${ }^{+}$immune cells, $\mathrm{CI}$, can also ascend to dominate the bacterial population (Figure S3C). In this latter simulation the probability of the acquisition of spacer upon infection was 10 times as great as that in Figures S3A and $\mathrm{B}, \mathrm{x}=1.667 \times 10^{-7}$ rather than $\mathrm{x}=1.667 \times 10^{-8}$. 


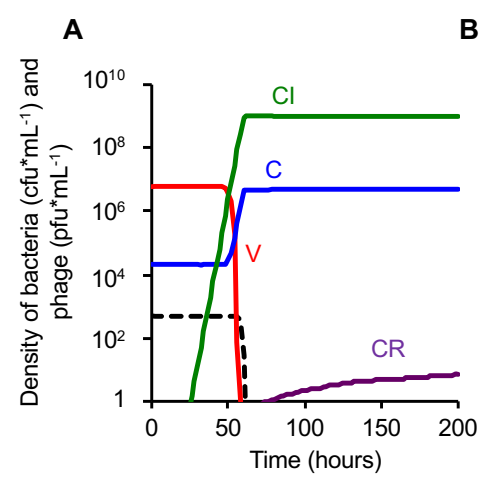

B

C
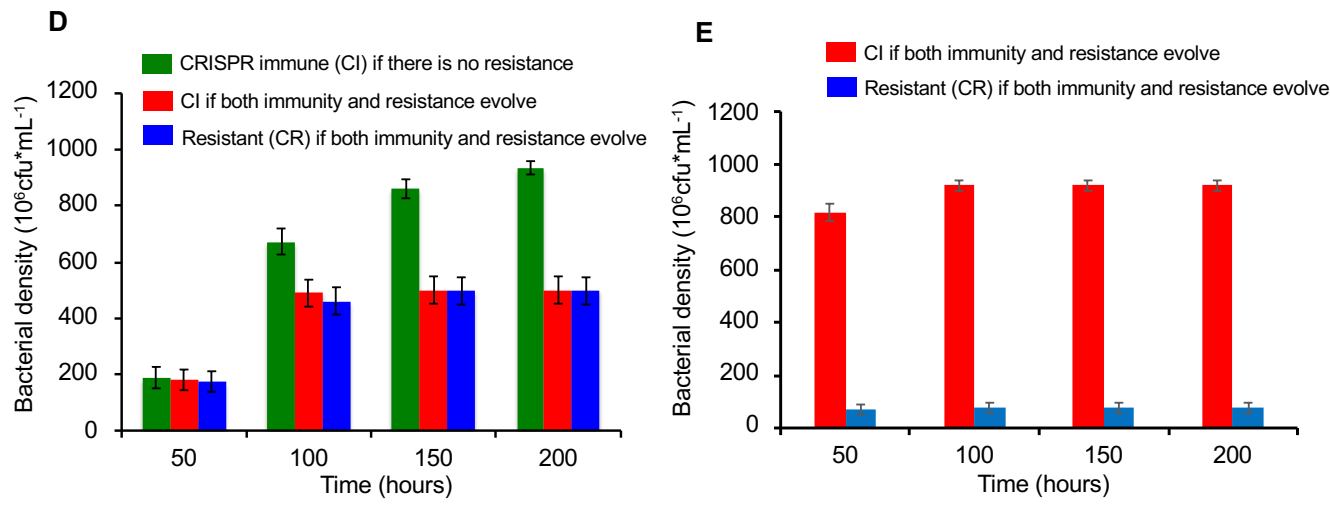

Figure S2: Establishment of immune, CI, and resistant, CR, cells in a sensitive CRISPR ${ }^{+}$population, C. Standard parameters $\mathrm{v}_{\mathrm{C}}=\mathrm{v}_{\mathrm{CI}}=\mathrm{v}_{\mathrm{CR}}=0.7, \delta=10^{-7}, \beta=50, \mathrm{e}=5 \times 10^{-7}, \mathrm{k}=1, \mathrm{RR}=500, \mathrm{w}=0.1, \mathrm{r}(0)=500, \mu_{\mathrm{SR}}=10^{-8}$ $\mu_{\mathrm{RS}}=10^{-8}$, and the total volume of the vessel is $\mathrm{Vol}=100 \mathrm{ml}$. The initial densities of bacteria and phage in these simulations are at the equilibrium for a phage-limited population, respectively, $\mathrm{C}^{*}=2 \times 10^{4}, \mathrm{~V}^{*}=6 \times 10^{6}$, and $\mathrm{x}=1.667 \times 10^{-8}$ unless indicated otherwise. Changes in the densities of bacteria and phage, when $\mathrm{A}$ ) immunity, CI, arises and ascends to dominance before resistance, CR; B) resistance, CR, emerges and ascends to dominance before immune cells are generated or $\mathrm{C}$ ) resistance emerges and ascends shortly before immune cells emerge. D) The outcome of 100 independent simulations, mean and standard error of the density of CI and CR at different times, where the probability of spacer acquisition $\mathrm{x}=1.667 \mathrm{x} 10^{-8}$ (this figure is also shown in the main text, as Figure 1A) or E) or where the probability of picking up a spacers is $10 \mathrm{X}$ that of generating a mutant $\mathrm{x}=1.667 \times 10^{-7}$. Black dotted lines are resource concentration.

To determine the relationship between the initial frequencies of CRISPR ${ }^{+}$and CRISPR ${ }^{-}$on the conditions for $\mathrm{CRISPR}^{+}$cells to become established in CRISPR ${ }^{-}$population, we use Monte Carlo simulations, 200 runs with each set of parameters. We follow the changes in the density of $\mathrm{CRISPR}^{+}$cells at different at times for different initial frequencies of CRISPR ${ }^{+}$cells. As our criterion for the establishment of $\mathrm{CRISPR}^{+}$in a CRISPR- population, we consider the change in the density of CRISPR ${ }^{+}$between time 0 and 200 hours. By this criterion $\mathrm{CRISPR}^{+}$can become established in populations of CRISPR ${ }^{-}$when the initial frequency of CRISPR ${ }^{+}$is as low as $10^{-3}$, depending on whether immunity is generated at a low or high rate relative to mutation (Figures S3D and S3E). In considering this, it is worth noting that in the runs with the initial frequency of 
$\mathrm{CRISPR}^{+}$of $10^{-3}, \mathrm{CRISPR}^{+}$dominated at 200 hours in only 2 out of the 200 runs, with both the lower and higher rates of CRISPR-Cas mediated immunity.

Overall, we interpret these simulation results to suggest that if the frequency of CRISPR ${ }^{+}$cells that are initially neither resistant or immune to the phage is less than $10^{-3}$, the likelihood of CRISPRCas immunity successfully becoming established in a CRISPR ${ }^{-}$population at equilibrium with the phage is negligible. This is particularly important when considering the establishment of CRISPR ${ }^{+}$ cells in CRISPR ${ }^{-}$populations by horizontal gene transfer when the initial frequency of $\mathrm{CRISPR}^{+}$ cells is going to be low.

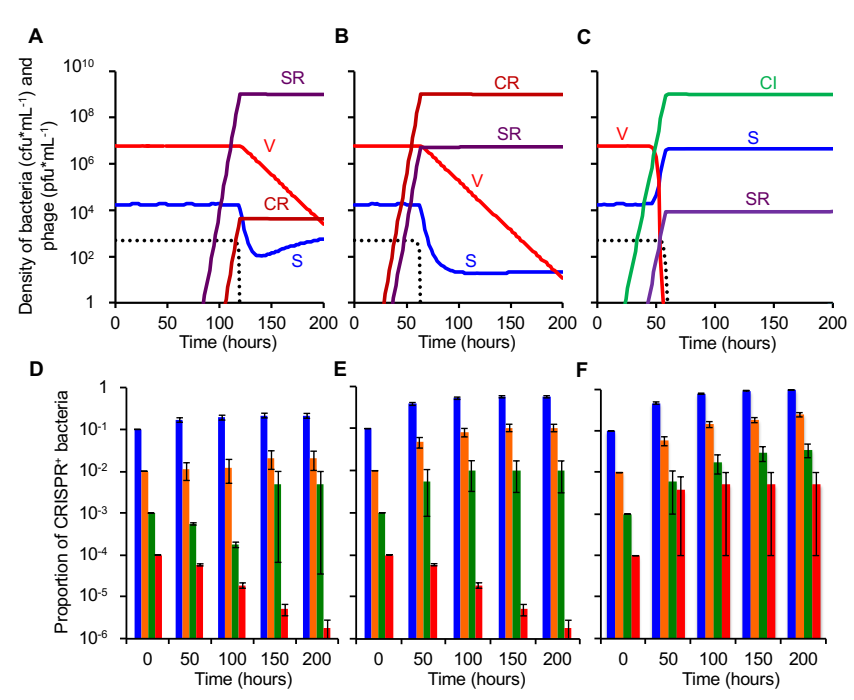

Figure S3. Establishment of CRISPR ${ }^{+}$in a CRISPR ${ }^{-}$phage sensitive population at equilibrium with lytic phage. Standard parameters, $\mathrm{v}_{\mathrm{S}}=\mathrm{v}_{\mathrm{R}}=\mathrm{v}_{\mathrm{C}}=\mathrm{v}_{\mathrm{CI}}=\mathrm{v}_{\mathrm{CR}}=0.7, \delta=10^{-7}, \beta=50, \mathrm{e}=5 \times 10^{-7}, \mathrm{k}=1, \mathrm{RR}=500, \mathrm{w}=0.1$, $\mu_{\mathrm{SR}}=10^{-8}, \mu_{\mathrm{RS}}=10^{-8}$ (save for $\mathrm{F}$ ) and the total volume of the vessel is $\mathrm{Vol}=100 \mathrm{ml}$. In this simulation the equilibrium population of sensitive bacteria includes both CRISPR ${ }^{-}$and CRISPR ${ }^{+}$. A and B) changes in the densities of bacteria and phage in populations initiated with $10 \% \mathrm{CRISPR}^{+}, \mathrm{C}$, and $90 \% \mathrm{CRISPR}^{-}, \mathrm{S}$, and $\mathrm{x}=1.667 \times 10^{-8}$. A) CRISPR ${ }^{-}$resistant cells, SR, evolved to dominate. B) $\mathrm{CRISPR}^{+}$resistant cells, CR, evolved to dominate. C) $\mathrm{x}=1.667 \times 10^{-7}$, and CRISPR- immune cells, CI, evolved to dominate. D) Monte Carlo simulations, mean and standard errors in the frequency of CRISPR ${ }^{+}$cells in 200 simulated populations initiated with different frequencies of CRISPR ${ }^{+}, \mathrm{C}$, and CRISPR', $\mathrm{S}$, at equilibrium with the phage with $\mathrm{x}=$ $1.667 \times 10^{-8}$ (this figure is also shown in the main text, as Figure $1 \mathrm{~B}$ ). Blue $=0.1$, orange $=0.01$, green $=0.001$, red $=0.0001$ initial frequency of $\mathrm{CRISPR}^{+}$. E) Monte Carlo simulations, mean and standard errors in the frequency of CRISPR ${ }^{+}$cells. 200 simulated populations initiated with different frequencies of CRISPR ${ }^{+}, \mathrm{C}_{\text {, }}$ and CRISPR', S, at equilibrium with the phage with $\mathrm{x}=1.667 \times 10^{-7}$. Color coding as in D. F) Monte Carlo simulations, mean and standard error in the frequency of CRISPR ${ }^{+}$cells. 200 simulated populations initiated with different frequencies of CRISPR ${ }^{+}, \mathrm{C}$, and CRISPR $;$, at equilibrium with the phage with $\mathrm{x}=1.667 \times 10^{-}$ ${ }^{7}$, and no resistance possible $\mu_{\mathrm{SR}}=\mu_{\mathrm{RS}}=0$. Color coding as in D. Black dotted lines are resource concentration. 
(iii) Caveats: In choosing the parameters for these simulations of lytic phage selecting for CRISPRCas mediated immunity, we are making two assumptions that can affect the predictions. One, all of the populations are equally fit (i.e. they have the same maximum growth rates). For example, if CRISPR-Cas engenders a cost relative to sensitive cells, the conditions for the establishment of immunity in a CRISPR ${ }^{-}$or $\mathrm{CRISPR}^{+}$population are going to be less than that predicted by this model. If CRISPR-Cas is less costly than envelope resistance, $\mathrm{v}_{\mathrm{CI}}>\mathrm{v}_{\mathrm{CR}}$, immunity is more likely to evolve than resistance. Two, the populations of sensitive cells being invaded, $\mathrm{C}$ or $\mathrm{S}$, are at equilibrium with the phage. If indeed these populations were confronted by phage, they may already be dominated by resistant cells.

\section{Population dynamics of temperate phage and bacteria with and without a CRISPR-Cas system.}

The Model: In this model, diagrammed in Figure S4, there is a single population of temperate phage, $\mathrm{P}$, and two types of bacteria: those that are $\mathrm{CRISPR}^{+}$(i.e., carry a functional CRISPR-Cas system) and those that are CRISPR ${ }^{-}$(i.e. lack a functional CRISPR-Cas system). The CRISPRbacteria can exist in two states; they can either be sensitive non-lysogens, or they can be lysogens (carry the prophage), respectively $\mathrm{S}$ and L. The CRISPR ${ }^{+}$populations can be present in three states: sensitive non-lysogens, C, lysogens, CL, and CRISPR immune, CI. The phage can exist in three states, as free phage, $\mathrm{P}$, or as prophage in CRISPR ${ }^{-}$lysogens, $\mathrm{L}$, or as CRISPR ${ }^{+}$lysogens, CL. The bacteria grow at maximum rates, $\mathrm{v}_{\mathrm{S}}, \mathrm{v}_{\mathrm{L}}, \mathrm{v}_{\mathrm{C}}, \mathrm{v}_{\mathrm{CL}}$, and $\mathrm{v}_{\mathrm{CI}}$ per cell per hour. The phage adsorb to the bacteria at a rate proportional to the product of their density, that of the bacteria, and a rate parameter, $\delta$ cell $\mathrm{x} \mathrm{ml} /$ hour (143). The $\mathrm{S}$ and $\mathrm{C}$ populations support the lytic replication of the phage. As in (145) with a probability $\lambda(0 \leq \lambda \leq 1)$ upon infection with lytic phage, the $\mathrm{S}$ and $\mathrm{C}$ populations become lysogens, respectively $\mathrm{L}$ and $\mathrm{CL}$. These lysogens are immune to superinfection with the temperate phage, as are the $\mathrm{CRISPR}^{+}$immune cells, CI; phage that infect these immune cells are removed from the population. CRISPR ${ }^{+}$immune cells, CI, are generated in two ways, from existing lysogens, at rate y per cell per hour, and by infection with $\mathrm{P}$, with a probability $\mathrm{x}$ per infected cell. In addition to being produced by lytic infections, with a burst size $\beta$, free temperate phage are generated by induction of the lysogens, at a rate i per cell per hour. When they lose the prophage, CRISPR- lysogens revert to sensitivity, S, and when they lose the prophage, $\mathrm{CRISPR}^{+}$lysogens revert to sensitivity, C. In this model, we assume CRISPR-Cas is not lost. 


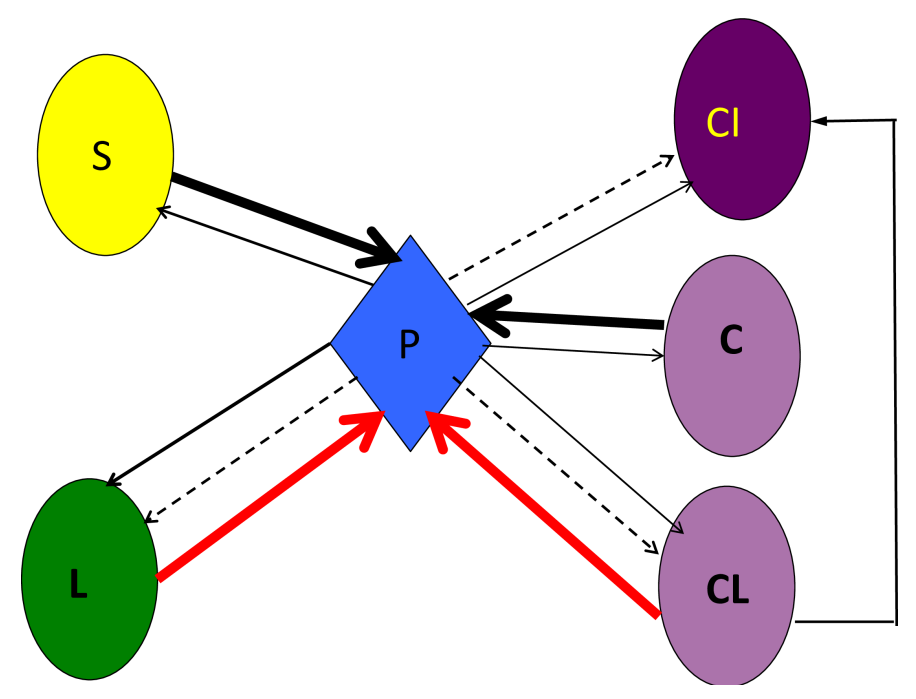

Figure S4. Model of the population dynamics of temperate phage and bacteria with and without CRISPRCas systems. $\mathrm{P}$ is the density of free phage, $\mathrm{S}$, and $\mathrm{L}$ are respectively CRISPR sensitive and lysogenic bacteria. C, CL, and CI are, respectively, the designations and densities of CRISPR ${ }^{+}$bacteria that are sensitive to the free phage, lysogens, and immune cells. Solid red lines denote the production of free phage by induction of the lysogens. The thick solid black lines denote the production of phage by lytic infection. The thin broken lines denote the loss of the phage due to the adsorption to immune cells, L, CL, and CI. The spacers responsible for the immunity of non-lysogens, $\mathrm{C}$, are picked up by infection with the phage and from CRISPR ${ }^{+}$lysogen.

With these definitions and assumptions, the rates of change in the densities of the bacterial populations, free phage, and the concentration of the limiting resource are given by the following set of coupled differential equations.

$$
\begin{aligned}
& \frac{d r}{d t}=w \cdot(R R-r)-e \cdot \psi(r) \cdot\left(v_{S} \cdot S+v_{L} \cdot L+v_{C} \cdot C+v_{C L} \cdot C L+v_{C I} \cdot C I\right) \\
& \frac{d S}{d t}=v_{S} \cdot S \cdot \psi(r)-\delta \cdot P \cdot S-w \cdot S \\
& \frac{d L}{d t}=v_{L} \cdot L \cdot \psi(r)+\delta \cdot P \cdot S \cdot \lambda-i \cdot L-w \cdot L \\
& \frac{d C}{d t}=v_{C} \cdot C \cdot \psi(r)-\delta \cdot P \cdot C-w \cdot C \\
& \frac{d C L}{d t}=v_{C L} \cdot C L \cdot \psi(r)+\delta \cdot P \cdot C \cdot \lambda-i \cdot C L-y \cdot C L-w \cdot C L \\
& \frac{d C I}{d t}=v_{C I} \cdot C I \cdot \psi(r)+x \cdot \delta \cdot P \cdot C+y \cdot C L-w \cdot C I \\
& \frac{d P}{d t}=\delta \cdot P \cdot S \cdot(1-\lambda) \cdot(\beta-1)+\delta \cdot P \cdot C \cdot(1-\lambda-x) \cdot(\beta-1)+i \cdot(L+C L) \cdot \beta-\delta \cdot P \cdot(C I+L+C L)-w \cdot P \\
& w h e r e \quad \psi(r)=\frac{r}{(r+k)} \\
& \frac{\text { w }}{d}
\end{aligned}
$$


Temperate phage-mediated selection for CRISPR-Cas: We open our analysis of the properties of this model with an exploration of the conditions under which CRISPR-Cas immune cells, CI, will invade and become established in a $\mathrm{CRISPR}^{+}$population. In Figure S5A, we consider the dynamics of the invasion of a population of bacteria immune to the temperate phage, CI, into a population initially composed of sensitive non-lysogens and free temperate phage, $\mathrm{C}$ and $\mathrm{P}$. Due to lytic infection and the generation of lysogens, the sensitive, $\mathrm{C}$ population is lost. The density of the free temperate phage increases rapidly and the $\mathrm{C}$ population is converted into lysogens CL. In this simulation, the carriage of the prophage reduces the fitness of the lysogens, CL relative to $\mathrm{C}$ and CI. Immune cells, CI, are produced and, because of their fitness advantage over the lysogens, replace the lysogens as the dominant population of bacteria. The density of free phage declines when immune population ascends to dominate. In the absence of CRISPR-Cas mediated immunity, there would be a stable equilibrium with lysogens and temperate phage, CL and P (145), which can be seen in Figure S5B. In this and the following simulation, Figure S5C, we consider the invasion of CRISPR-Cas immunity, CI, in populations at equilibrium with the temperate phage. In the absence of selection for or against lysogens, the immune cells, CI, increase slowly, due to the conversion of lysogens into immune cells, $\mathrm{CL} \rightarrow \mathrm{CI}$. The rate of increase of the CRISPR-Cas immune cells is proportional to the fitness cost of carrying the prophage (Figure S5C).

In Figures S5D-F, we consider the invasion of $\mathrm{CRISPR}^{+}$cells in a CRISPR- population. In Figure $5 \mathrm{D}$ we follow the dynamics of temperate phage, lysogeny and the invasion of CRISPR ${ }^{+}$cells (CI and CL) in a population initiated with sensitive non-lysogens, $\mathrm{S}$ and temperate phage, $\mathrm{P}$ and a 100 $\mathrm{CRISPR}^{+}$sensitive non-lysogens. The phage density increases initially and, within short order, the CRISPR- lysogens, L, ascend. While the invading population of CRISPR ${ }^{+}$sensitive non-lysogens, $\mathrm{C}$ are lost due to the phage, they are converted into lysogens, CL, which are maintained for a while as a minority population. CRISPR-Cas immune cells, CI are generated and, because in this simulation they have a selective advantage over the lysogens, they increase in density, invade, and will eventually become the dominant population of bacteria. In Figure S5E we consider a population of CRISPR-lysogens at equilibrium with the temperate phage and a minority population of CRISPR immune cells, CI in the absence of selection for or against the lysogens, L and CL. Under these conditions, the density of the invading $\mathrm{CRISPR}^{+}$population does not increase or decrease. If, the prophage reduces the fitness of lysogens, the CRISPR ${ }^{+}$population will invade, Figure S5F with the rate of ascent inversely proportional to the costs. If the prophage augments the fitness of the lysogens, relative to non-lysogens, the CRISPR ${ }^{+}$population will be selected against. 


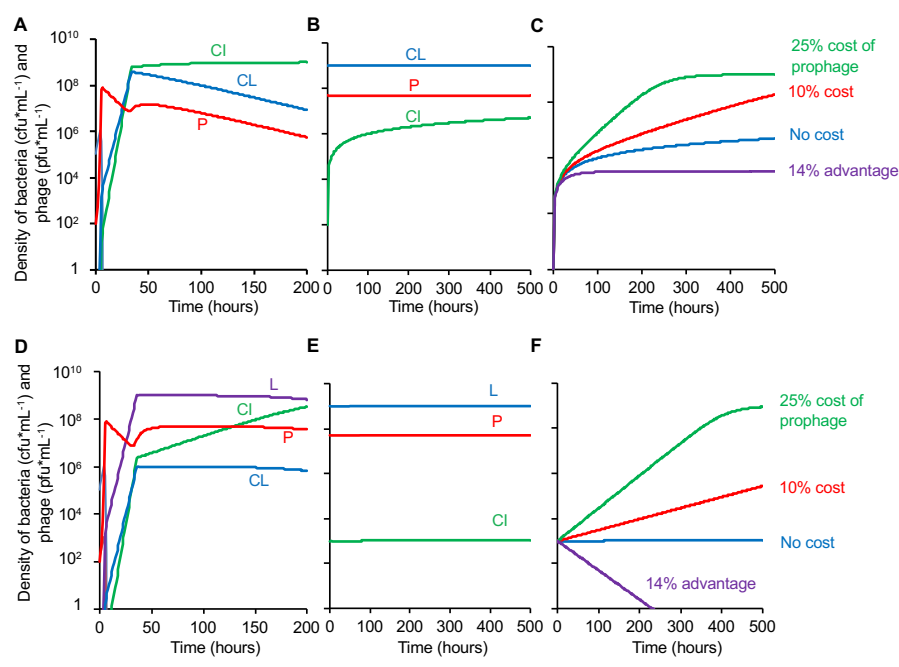

Figure S5 Invasion conditions for CRISPR-Cas mediated immunity in populations of bacteria and temperate phage. Standard parameters: $\mathrm{RR}=500, \mathrm{w}=0.1, \mathrm{k}=1.0, \mathrm{e}=5 \times 10^{-7}, \quad=10^{-7}, \quad=50, \mathrm{i}=10^{-4}, \quad=10-3$, $\mathrm{x}=\mathrm{y}=10^{-5}$. A, B and C) Establishment of immunity in a CRISPR ${ }^{+}$population. A) Dynamics of the changes in the densities of free phage, $\mathrm{CRISPR}^{+}$lysogens, and $\mathrm{CRISPR}^{+}$immune bacteria, in populations initiated with free phage and sensitive $\mathrm{CRISPR}^{+}$bacteria, with a $25 \%$ fitness cost of lysogens, $\mathrm{v}_{\mathrm{C}}=\mathrm{v}_{\mathrm{Cl}}=0.70$, $\mathrm{v}_{\mathrm{CL}}=0.525$. The light blue line corresponds to the initially sensitive cells, which are quickly lost from the population. B and C) Populations at equilibrium with lysogens and free temperate phage. B) Changes in the densities of bacteria and phage in the absence of selection for or against lysogens, $\mathrm{v}_{\mathrm{C}}=\mathrm{v}_{\mathrm{CL}}=\mathrm{v}_{\mathrm{Cl}}=0.7$. C) Changes in the densities of CRISPR-Cas immune cells with different cost of lysogeny, no cost, $\mathrm{v}_{\mathrm{C}}=\mathrm{v}_{\mathrm{Cl}}=0.7$, $\mathrm{v}_{\mathrm{CL}}=0.7$, a $25 \%$ costs $\mathrm{v}_{\mathrm{CL}}=0.525$, a $10 \%$ cost $\mathrm{v}_{\mathrm{CL}}=0.63$, with lysogens $14.3 \%$ more fit than non-lysogens $\mathrm{v}_{\mathrm{CL}}=1.0 . \mathrm{D}, \mathrm{E}$, and F) Establishment of bacteria with CRISPR-Cas (CRISPR ${ }^{+}$) in a CRISPR ${ }^{-}$population. D) Dynamics of the changes in density of free phage, CRISPR ${ }^{-}$and $\mathrm{CRISPR}^{+}$bacteria in a population initiated with free temperate phage, and CRISPR ${ }^{-}$and $\mathrm{CRISPR}^{+}$sensitive non-lysogens, with a $25 \%$ cost due to the carriage of the prophage $\mathrm{v}_{\mathrm{S}}=\mathrm{v}_{\mathrm{C}}=\mathrm{v}_{C l}=0.7, \mathrm{v}_{\mathrm{L}}=\mathrm{v}_{\mathrm{CL}}=0.525$. The light blue line corresponds to the initially sensitive cells, which are quickly lost from the population. E and F) Population dynamics of CRISPR ${ }^{+}$in a population of CRISPR ${ }^{-}$bacteria initially at equilibrium with the temperate phage. E) Changes in the densities of bacteria and phage in the absence of selection for or against lysogens $\mathrm{v}_{\mathrm{S}}=\mathrm{v}_{\mathrm{L}}=\mathrm{v}_{\mathrm{C}}=\mathrm{v}_{C L}=\mathrm{v}_{C I}=0.7$, F) Changes in the densities of CRISPR ${ }^{+}$cells with different costs of lysogeny, no cost $\mathrm{v}_{\mathrm{S}}=\mathrm{v}_{\mathrm{C}}=\mathrm{v}_{\mathrm{CI}}=0.7, \mathrm{v}_{\mathrm{L}}$ $=\mathrm{v}_{\mathrm{CL}}=0.7$, a $25 \%$ cost, $\mathrm{v}_{\mathrm{L}}=\mathrm{v}_{\mathrm{CL}}=0.525$, a $10 \%$ cost, $\mathrm{v}_{\mathrm{L}}=\mathrm{v}_{\mathrm{CL}}=0.63$, a $14.3 \%$ advantage $\mathrm{v}_{\mathrm{L}}=\mathrm{v}_{\mathrm{CL}}=1.0$.

In Figures S5D-F, we consider the invasion of CRISPR ${ }^{+}$cells in a CRISPR- population. In Figure $5 \mathrm{D}$ we follow the dynamics of temperate phage, lysogeny and the invasion of $\mathrm{CRISPR}^{+}$cells (CI and $\mathrm{CL}$ ) in a population initiated with sensitive non-lysogens, $\mathrm{S}$ and temperate phage, $\mathrm{P}$ and a 100 $\mathrm{CRISPR}^{+}$sensitive non-lysogens. The phage density increases initially and, within short order, the CRISPR- lysogens, L, ascend. While the invading population of CRISPR ${ }^{+}$sensitive non-lysogens, $\mathrm{C}$ are lost due to the phage, they are converted into lysogens, CL, which are maintained for a while 
as a minority population. CRISPR-Cas immune cells, CI are generated and, because in this simulation they have a selective advantage over the lysogens, they increase in density, invade, and will eventually become the dominant population of bacteria. In Figure S5E we consider a population of CRISPR-lysogens at equilibrium with the temperate phage and a minority population of CRISPR immune cells, CI in the absence of selection for or against the lysogens, L and CL. Under these conditions, the density of the invading $\mathrm{CRISPR}^{+}$population does not increase or decrease. If, the prophage reduces the fitness of lysogens, the CRISPR ${ }^{+}$population will invade, Figure S5F with the rate of ascent inversely proportional to the costs. If the prophage augments the fitness of the lysogens, relative to non-lysogens, the CRISPR ${ }^{+}$population will be selected against.

\section{Population dynamics of conjugative plasmids and bacteria with and without CRISPR- Cas mediated immunity:}

The Model: There are two populations of CRISPR- cells, one that carries the plasmid and one that does not, DP, and S, respectively, and three populations of CRISPR ${ }^{+}$cells, plasmid-free, plasmidbearing, and immune, respectively $\mathrm{C}, \mathrm{CP}$, and CI. These populations grow at maximum rates, vs, $\mathrm{V}_{\mathrm{P}}, \mathrm{V}_{\mathrm{C}}, \mathrm{V}_{\mathrm{CP}}, \mathrm{V}_{\mathrm{CI}}$ per cell per respectively. The plasmids are transferred at rates proportional to the product of the densities of plasmid-bearing and plasmid-free cells and a rate parameter, $\gamma(146)$. $\mathrm{CRISPR}^{+}$cells, C, acquire spacers and become immune to infection with the plasmid, CI, at a rate proportional to the product of their densities, the rate constant of plasmid transfer, $\gamma$, and the probability of picking up a spacer $\mathrm{x}(0 \leq \mathrm{x} \leq 1)$ upon conjugation. Immune CRISPR ${ }^{+}$cells can also be generated from plasmid-bearing $\mathrm{CP}$ at a rate y per cell per hour. Plasmids are lost by vegetative segregation at a rate $\tau$ per cell per hour, resulting in DP cells reverting back to $\mathrm{S}$ and CP cells reverting back to $\mathrm{C}$.

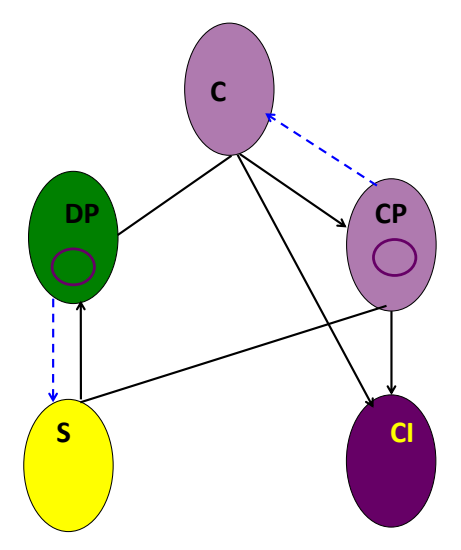

Figure S6 Model of the population dynamics conjugative plasmids and bacteria with and without CRISPR. There are two populations of CRISPR ${ }^{-}$cells, plasmid-free, and plasmid bearing, S, and DP. There are three populations of CRISPR ${ }^{+}$bacteria, those that are plasmid-free, those that carry the plasmid and those that are immune to the plasmid, respectively, C, CP, and CI. Plasmids are transferred to plasmid-free cells at a rate proportional to the product of their densities and a rate constant, $\gamma$. Immune, cells, CI are produced by infection of $\mathrm{C}$ by mating with a plasmid bearing cells or from a transition from $\mathrm{CP}$ to $\mathrm{CI}$. 
With these definitions and assumptions, a chemostat habitat and resource-limited growth, the rates of change in the densities of the different populations and concentration of the resource are given by the following array of coupled differential equations.

$$
\begin{aligned}
& \frac{d r}{d t}=w \cdot(R R-r)-e \cdot \psi(r) \cdot\left(v_{S} \cdot S+v_{D P} \cdot D P+v_{C} \cdot C+v_{C P} \cdot C P+v_{C I} \cdot C I\right) \\
& \frac{d S}{d t}=v_{S} \cdot \psi(r) \cdot S-\gamma \cdot S \cdot(D P+C P)+\tau \cdot D P-w \cdot S \\
& \frac{d D P}{d t}=v_{D P} \cdot \psi(r) \cdot D P+\gamma \cdot S \cdot(D P+C P)-\tau \cdot D P-w \cdot D P \\
& \frac{d C}{d t}=v_{C} \cdot \psi(r) \cdot C-\gamma \cdot C \cdot(D P+C P)+\tau \cdot C P-w \cdot C \\
& \frac{d C P}{d t}=v_{C P} \cdot \psi(r) \cdot C P+\gamma \cdot(1-x) \cdot C \cdot(D P+C P)-\tau \cdot C P-y \cdot C P-w \cdot C P \\
& \frac{d C I}{d t}=v_{C I} \cdot \psi(r) \cdot C I+x \cdot \gamma \cdot C \cdot(D P+C P)+y \cdot C P-w \cdot C I \\
& \text { where } \psi(r)=\frac{r}{(r+k)}
\end{aligned}
$$

When bacteria carrying conjugative plasmids are introduced into receptive populations of plasmidfree cells in continuous culture, the plasmid can sweep through the population and convert the plasmid-free cells into plasmid bearing (146). These dynamics can be seen in Figure S7A, where we consider the invasion of a CRISPR-Cas immune population, CI, into a population of plasmidbearing and plasmid-free $\mathrm{CRISPR}^{+}$cells, $\mathrm{C}$ and $\mathrm{CP}$. In these simulations, the plasmid engenders of $25 \%$ fitness cost; the immune bacteria, CI ascend and eventually replace the plasmid-bearing cells as the dominant population. With the parameters considered in the simulations, in the absence of immunity, CI, there are stable equilibria between the plasmid-bearing and plasmid-free bacteria (146). In the absence of a cost due to the carriage of the plasmid, the initially rare immune population, CI, increase in density in a $\mathrm{CRISPR}^{+}$population at equilibrium with the plasmid (Figure S7B). This increase in the density of the invading immune population can be attributed to the production of immune cells by the dominant population of plasmid bearing cells, $\mathrm{CP} \rightarrow \mathrm{CI}$ at a rate $y=10^{-5}$ per cell per hour. If $y=0$, the density of this immune population would remain at its initial level ("data" not shown). The rate at which the density of immune cells increases is inversely proportional to the fitness cost of carrying the plasmid (Figure S7C). As was the case for where there was no cost associated with the carriage of the plasmid, the increase and leveling off in the density of CI when the plasmid-confers a selective advantage can be attributed to the production of immune cells by the plasmid bearing cells. If not for this, the density of the invading population of immune cells would decline. 


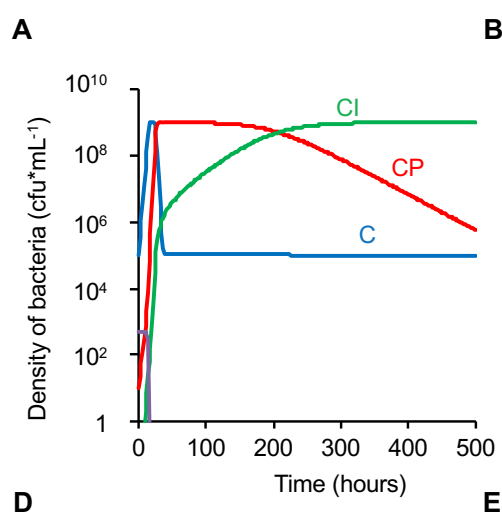

B

C
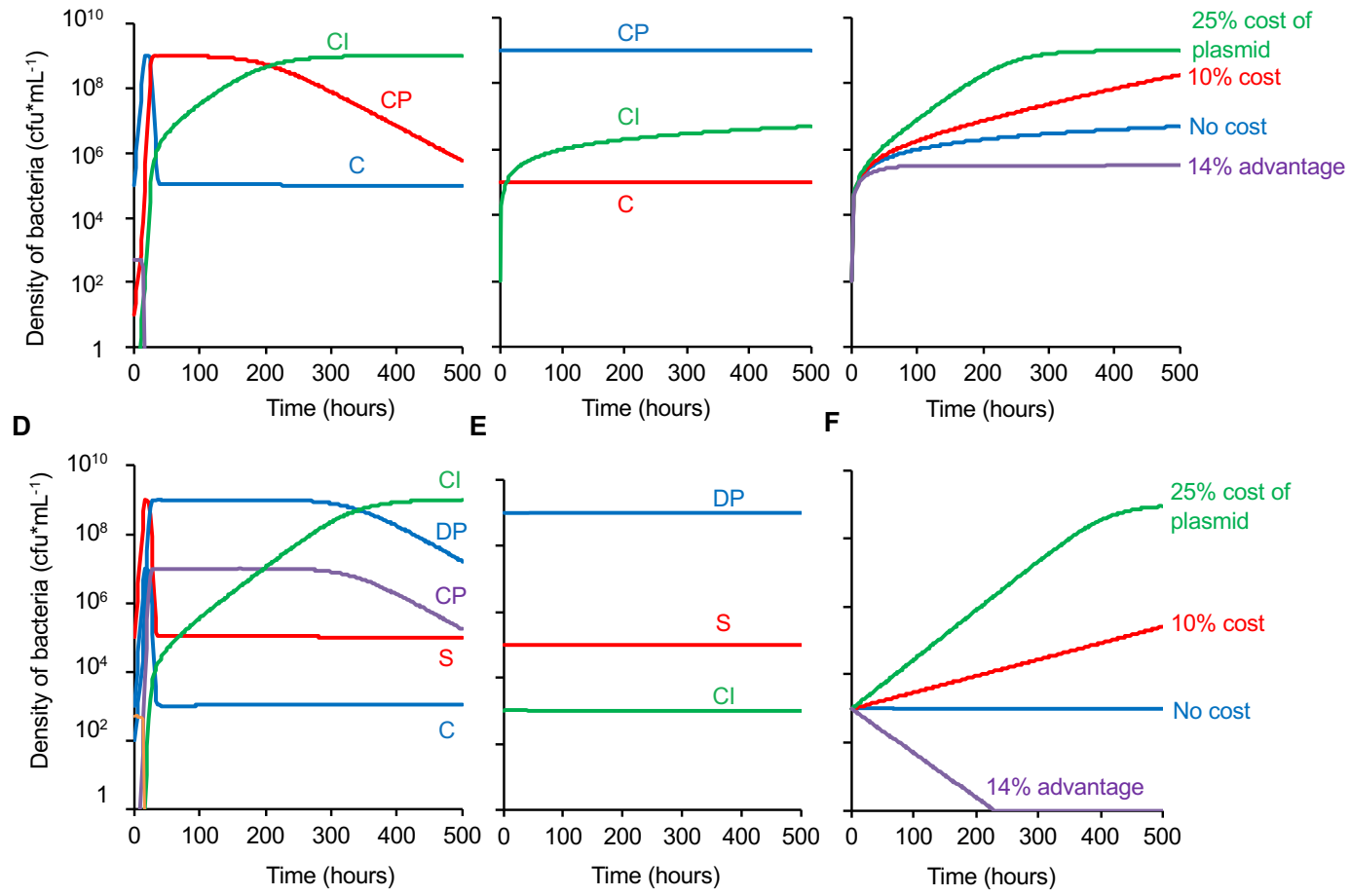

Figure S7. Conditions for the invasion of CRISPR-Cas immunity in populations with conjugative plasmids. Standard parameters, $R R=500, w=0.10, e=5 \times 10^{-7}, k=1.0, \gamma=10^{-9}, \tau=10^{-4}, x=10^{-4}, y=10^{-4}$. Changes in the densities of bacteria. A, B and C) Invasion CRISPR-Cas mediated immunity in a CRISPR ${ }^{+}$population. A) Dynamics of plasmid transfer and the ascent of a CRISPR-Cas immune, CI, population, when there is a $25 \%$ cost of plasmid carriage: $\mathrm{v}_{\mathrm{C}}=\mathrm{v}_{\mathrm{Cl}}=0.7, \mathrm{v}_{\mathrm{CP}}=0.525$. B and C) Invasion of CRISPR-Cas immune cells, CI, in population at equilibrium with plasmid bearing and plasmid-free cells, CP. B) Changes in the densities of immune cells, CI, in the absence of selection for or against the carriage of the plasmids: $\mathrm{v}_{\mathrm{C}}=\mathrm{v}_{\mathrm{CP}}=\mathrm{v}_{\mathrm{Cl}}=0.7$. C) Invasion of a CRISPR-Cas immune bacteria, CI, in populations of plasmid-free $\mathrm{CRISPR}^{+}$bacteria with different costs for the carriage of the plasmid: $\mathrm{v}_{\mathrm{C}}=\mathrm{v}_{\mathrm{CI}}=0.7, \mathrm{v}_{\mathrm{CP}}=0.7$ (no cost), $\mathrm{v}_{\mathrm{CP}}=0.525\left(25 \%\right.$ cost), $\mathrm{v}_{\mathrm{CP}}$ $=0.63(10 \%$ cost $), \mathrm{v}_{\mathrm{CP}}=1.0(14 \%$ advantage $)$. D-F) Invasion of a CRISPR population by bacteria carrying CRISPR-Cas immune systems (CRISPR ${ }^{+}$). D) Dynamics of plasmid transfer and the CRISPR ${ }^{+}$bacteria, CI and $\mathrm{CP}$, in a CRISPR population with a $25 \%$ cost of plasmid carriage: $\mathrm{v}_{\mathrm{S}}=\mathrm{v}_{\mathrm{D}}=\mathrm{v}_{\mathrm{C}}=\mathrm{v}_{\mathrm{CI}}=0.7, \mathrm{v}_{\mathrm{DP}}=\mathrm{v}_{\mathrm{CP}}=0.525$. $\mathrm{E}$ and $\mathrm{F}$ ) Invasion of CRISPR ${ }^{+}$cells in a CRISPR population at equilibrium with the plasmid, DP and S. E) Changes the densities CRISPR ${ }^{-}$plasmid-bearing and plasmid free cells, DP and S and a CRISPR-Cascontaining population (CRISPR ${ }^{+}$) with plasmid immunity, $\mathrm{CI}$, in the absence of selection for or against the carriage of the plasmid. $\mathrm{v}_{\mathrm{S}}=\mathrm{v}_{\mathrm{DP}}=\mathrm{v}_{\mathrm{C}}=\mathrm{v}_{\mathrm{CP}}=\mathrm{v}_{\mathrm{CI}}=0.7$. F) Changes in the densities of CRISPR ${ }^{+}$bacteria with different costs of the carriage of the plasmid with different costs for the carriage of the plasmid: $\mathrm{v}_{\mathrm{C}}=\mathrm{v}_{\mathrm{CI}}=0.7$, $\mathrm{v}_{\mathrm{CP}}=0.7$ (no cost), $\mathrm{v}_{\mathrm{CP}}=0.525(25 \%$ cost $), \mathrm{v}_{\mathrm{CP}}=0.63(10 \%$ cost $), \mathrm{v}_{\mathrm{CP}}=1.0(14 \%$ advantage $)$.

In Figure S7D, we consider the invasion of $\mathrm{CRISPR}^{+}$cells into a CRISPR ${ }^{-}$population with a conjugative plasmid. We follow the changes in the densities of the different populations of plasmid-free and plasmid bearing cells in a community initiated with plasmid-free and plasmidbearing CRISPR- bacteria, S and DP, and a minority population of CRISPR-Cas immune cells, CI. In this simulation, the plasmid engenders of $25 \%$ fitness cost and the immune bacteria, CI ascend. 
In Figure S7E and F, we consider the invasions of bacteria with CRISPR-Cas immune system into a population of $\mathrm{S}$ and DP at equilibrium in the absence of selection for or against the carriage of the plasmid. Under these conditions, the density of the CRISPR-Cas immune cells, CI remains unchanged. If the plasmid engenders a fitness cost, the immune cells invade at a rate that inversely proportional to the cost of the plasmid (Figure S7F).

The utility and limits of the models

Richard Levins argued that in constructing mathematical models in population biology one has to, sacrifice generality to realism and precisions, sacrifice realism to generality and precision, or sacrifice precision to realism and generality (147). The models developed here are in this last, heuristic, tradition. Their role is to identify the factors that govern the conditions under which CRISPR-Cas immunity will evolve and the relative contributions of these parameters to this evolution. The parameters of these models can be independently estimated in experimental populations of bacteria and archaea with lytic and temperate phage or conjugative plasmids and the hypotheses generated from their analysis tested in experimental populations of bacteria and archaea with phage and plasmids.

\section{REFERENCES}

1. J. Monod, The growth of bacterial cultures. Annual Review of Microbiology 3, 371-394 (1949).

2. F. M. Stewart, B. R. Levin, Resource partitioning and the outcome of interspecific competition: a model and some general considerations. American Naturalist 107, 171-198 (1973).

3. B. R. Levin, F. M. Stewart, L. Chao, Resource - limited growth, competition , and predation: a model and experimental studies with bacteria and bacteriophage. American Naturalist 977, 3-24 (1977).

4. J. Gurney, M. Pleska, B. R. Levin, Why put up with immunity when there is resistance: an excursion into the population and evolutionary dynamics of restriction-modification and CRISPR-Cas. Philos Trans R Soc Lond B Biol Sci 374, 20180096 (2019).

5. W. N. Chaudhry et al., Leaky Resistance and the conditions for the existience of lytic bacteriophage. PLoS Biology 16:e2005971 (2018).

6. F. Stewart, B. Levin, The population biology of bacterial viruses: why be temperate. Theoretical population biology 26, 93-117 (1984).

7. F. M. Stewart, B. R. Levin, The Population Biology of Bacterial Plasmids: A PRIORI Conditions for the Existence of Conjugationally Transmitted Factors. Genetics 87, 209228 (1977).

8. R. Levins, Strategy of Model Building in Population Biology. American Scientist 54, 421431 (1966). 
Table S1 Parameters and Variables

\begin{tabular}{|c|c|c|}
\hline Common Variables and Parameters & $\begin{array}{l}\text { Symbol and } \\
\text { dimensions }\end{array}$ & Value -Range \\
\hline Resource concentration in the habitat & $\mathrm{r} \mu \mathrm{g} / \mathrm{ml}$ & $0-500 \mu \mathrm{g} / \mathrm{ml}$ \\
\hline Resource concentration in the reservoir & $\mathrm{RR} \mu \mathrm{g} / \mathrm{ml}$ & $500 \mu \mathrm{g} / \mathrm{ml}$ \\
\hline Volume of the habitat & Vol & $100 \mathrm{ml}$ \\
\hline Flow rate into and out of the habitat & w ml per hour & 0.10 \\
\hline$r$ when the growth is half its maximum & $\mathrm{k} \mu \mathrm{g} / \mathrm{ml}$ & $1.0 \mathrm{ml}$ \\
\hline Conversion efficiency (resource/cell) & $e-\mu g / c e l l$ & $5 \times 10^{-7}$ \\
\hline \multicolumn{3}{|l|}{ Lytic Phage Model } \\
\hline Density of the phage & $\mathrm{V}$ particles per $\mathrm{ml}$ & $0-10^{9}$ \\
\hline Density of phage sensitive CRISPR ${ }^{-}$ & S cells per $\mathrm{ml}$ & $0-10^{9}$ \\
\hline Density of phage resistant CRISPR- bacteria & SR cells per $\mathrm{ml}$ & $0-10^{9}$ \\
\hline Density of phage sensitive CRISPR ${ }^{+}$bacteria & $\mathrm{C}$ cells per $\mathrm{ml}$ & $0-10^{9}$ \\
\hline Density of phage resistant CRISPR ${ }^{+}$bacteria & CR cells per $\mathrm{ml}$ & $0-10^{9}$ \\
\hline Density of phage immune CRISPR ${ }^{+}$bacteria & $\mathrm{Cl}$ cells per ml & $0-10^{9}$ \\
\hline Maximum growth rates & $\mathrm{v}_{\mathrm{S}}, \mathrm{v}_{\mathrm{R}}, \mathrm{v}_{\mathrm{C}}, \mathrm{v}_{\mathrm{CR}}, \mathrm{v}_{\mathrm{I}} \mathrm{hr}^{-1}$ & 0.7 \\
\hline Adsorption rate constant & $\delta$ - cells $\times \mathrm{ml} /$ hour & $10^{-7}$ \\
\hline Burst size & $\beta$ particles per cell & 50 \\
\hline Probability of the acquisition of a spacer & $\mathrm{x}$ per infected cell & $1.67 \times 10^{-8}, 1.67 \times 10^{-7}$ \\
\hline Mutation rates to resistance and sensitive & $\mu_{\mathrm{SR}}, \mu_{\mathrm{RS}}$ per cell per $\mathrm{hr}$ & $10^{-8}$ \\
\hline \multicolumn{3}{|l|}{ Temperate phage Model } \\
\hline Density of free temperate phage & $\mathrm{P}$ particle per $\mathrm{ml}$ & $0-10^{9}$ \\
\hline Density of phage sensitive CRISPR- bacteria & $\mathrm{S}$ cells per $\mathrm{ml}$ & $0-10^{9}$ \\
\hline Density of CRISPR ${ }^{-}$lysogenic CRISPR- bacteria & L cells per m; & $0-10^{9}$ \\
\hline Density of phage sensitive CRISPR ${ }^{+}$bacteria & $\mathrm{C}$ cells per $\mathrm{ml}$ & $0-10^{9}$ \\
\hline Density of CRISPR ${ }^{+}$lysogenic bacteria & CL cells per ml & $0-10^{9}$ \\
\hline Density of CRISPR- immune bacteria & $\mathrm{Cl}$ cells per $\mathrm{ml}$ & $0-10^{9}$ \\
\hline Maximum growth rate & $\mathrm{v}_{\mathrm{S}}, \mathrm{v}_{\mathrm{L}}, \mathrm{v}_{\mathrm{C}}, \mathrm{v}_{\mathrm{CL}}, \mathrm{v}_{\mathrm{Cl}} \mathrm{hr}^{-1}$ & $0.525-1.0$ \\
\hline Adsorption rate constant & $\delta$ - cells $\times \mathrm{ml} /$ hour & $10^{-8}$ \\
\hline Burst size & $\beta$ particles per cell & 50 \\
\hline Probability of the acquisition of a spacer & $\mathrm{x}$ per infected cell & $10^{-5}$ \\
\hline Rate of acquisition of spacers $\mathrm{CP} \rightarrow \mathrm{Cl}$ & y per cell per hour & $10^{-5}$ \\
\hline Probability of lysogeny & $\lambda$ per infection & $10^{-3}$ \\
\hline Induction rate & i per cell per hour & $10^{-4}$ \\
\hline \multicolumn{3}{|l|}{ Conjugative plasmid Model } \\
\hline Density of CRISPR ${ }^{-}$plasmid free bacteria & S & $0-10^{9}$ \\
\hline Density of CRISPR ${ }^{-}$plasmid-bearing bacteria & DP & $0-10^{9}$ \\
\hline Density of CRISPR ${ }^{+}$plasmid-free bacteria & C & $0-10^{9}$ \\
\hline Density of CRISPR ${ }^{+}$plasmid-bearing bacteria & $\mathrm{CP}$ & $0-10^{9}$ \\
\hline Density of CRISPR+ plasmid immune bacteria & $\mathrm{Cl}$ & $0-10^{9}$ \\
\hline Maximum growth rates & $\mathrm{v}_{\mathrm{S}}, \mathrm{v}_{\mathrm{DP}}, \mathrm{v}_{\mathrm{C}}, \mathrm{v}_{\mathrm{CP}}, \mathrm{v}_{\mathrm{Cl}} \mathrm{hr}^{-1}$ & 0.5251 .0 \\
\hline Rate constant of plasmid transfer & $\gamma$ cells $\times \mathrm{ml} /$ hour & $10^{-8}$ \\
\hline
\end{tabular}


bioRxiv preprint doi: https://doi.org/10.1101/2020.02.05.935965; this version posted July 25, 2020. The copyright holder has placed this preprint (which was not certified by peer review) in the Public Domain. It is no longer restricted by copyright. Anyone can legally share, reuse, remix, or adapt this material for any purpose without crediting the original authors. 